\title{
Variation and balance of positive air ion concentrations in a boreal forest
}

\author{
U. Hõrrak ${ }^{1}$, P. P. Aalto ${ }^{2}$, J. Salm ${ }^{1}$, K. Komsaare ${ }^{1}$, H. Tammet ${ }^{1}$, J. M. Mäkelä ${ }^{3}$ L. Laakso ${ }^{2}$, and M. Kulmala ${ }^{2}$ \\ ${ }^{1}$ Institute of Physics, University of Tartu, 18 Ülikooli St., 50090 Tartu, Estonia \\ ${ }^{2}$ Department of Physical Sciences, Division of Atmospheric Sciences P.O. Box 64, 00014 University of Helsinki, Finland \\ ${ }^{3}$ Tampere University of Technology, Institute of Physics, P.O. Box 692, 33101, Tampere, Finland
}

Received: 8 June 2007 - Published in Atmos. Chem. Phys. Discuss.: 3 July 2007

Revised: 14 November 2007 - Accepted: 10 January 2008 - Published: 12 February 2008

\begin{abstract}
Air ions are characterized on the basis of measurements carried out in a boreal forest at the Hyytiälä SMEAR station, Finland, during the BIOFOR III campaign in spring 1999. The air ions were discriminated as small ions (charged molecular aggregates of the diameter of less than $2.5 \mathrm{~nm}$ ), intermediate ions (charged aerosol particles of the diameter of 2.5-8 nm), and large ions (charged aerosol particles of the diameter of 8-20 nm). Statistical characteristics of the ion concentrations and the parameters of ion balance in the atmosphere are presented separately for the nucleation event days and non-event days. In the steady state, the ionization rate is balanced with the loss of small ions, which is expressed as the product of the small ion concentration and the ion sink rate. The widely known sinks of small ions are the recombination with small ions of opposite polarity and attachment to aerosol particles. The dependence of small ion concentration on the concentration of aerosol particles was investigated applying a model of the bipolar diffusion charging of particles by small ions. When the periods of relative humidity above $95 \%$ and wind speed less than $0.6 \mathrm{~m} \mathrm{~s}^{-1}$ were excluded, then the small ion concentration and the theoretically calculated small ion sink rate were closely negatively correlated (correlation coefficient $-87 \%$ ). However, an extra ion loss term of the same magnitude as the ion loss onto aerosol particles is needed for a quantitative explanation of the observations. This term is presumably due to the small ion deposition on coniferous forest. The hygroscopic growth correction of the measured aerosol particle size distributions was also found to be necessary for the proper estimation of the ion sink rate. In the case of nucleation burst events, the concentration of small positive ions followed the general balance equation, no extra ion loss in addition to the deposition on coniferous for-
\end{abstract}

Correspondence to: U. Hõrrak

(urmas.horrak@ut.ee) est was detected, and the hypothesis of the conversion of ions into particles in the process of ion-induced nucleation was not proved. The estimated average ionization rate of the air at the Hyytiälä station in early spring, when the ground was partly covered with snow, was about 6 ion pairs $\mathrm{cm}^{-3} \mathrm{~s}^{-1}$. The study of the charging state of nanometer aerosol particles (diameter $2.5-8 \mathrm{~nm}$ ) in the atmosphere revealed a strong correlation (correlation coefficient $88 \%$ ) between the concentrations of particles neutralized in the aerosol spectrometer and naturally positively charged particles (air ions) during nucleation bursts. The charged fraction of particles varied from $3 \%$ to $6 \%$ in accordance with the hypothesis that the particles are quasi-steady state charged.

\section{Introduction}

The formation and growth of ultrafine aerosol particles in the atmosphere have been studied during the last decade at many different locations around the world because of their possible impact on the radiation balance and thereby on the climate of the Earth (Kulmala et al., 2004a; Birmili et al., 2003; Tunved et al., 2003; Iida et al., 2006). Various theories have been elaborated to explain the mechanisms of new particle generation (e.g. Raes and Janssens, 1985; Yu and Turco, 2000, 2001; Laakso et al., 2002; Korhonen et al., 1999, Kulmala et al., 2000; Napari et al., 2002). Despite the frequently observed particle formation events, the microphysical mechanisms of nucleation have remained unclear because of the very small size of newly born particles (about $1-2 \mathrm{~nm}$ ). This size range is not within the scale of modern aerosol instruments using artificial charging of particles. Air ion spectrometers are suitable to measure naturally charged clusters and particles down to about $0.4 \mathrm{~nm}$, but the charging state

Published by Copernicus Publications on behalf of the European Geosciences Union. 
of newly born particles is not known in the atmosphere (due to different particle formation mechanisms). Experimental study of new particle formation in the atmosphere is complicated also because the size range of new particles coincides with the size range of small ions or cluster ions $(0.4-1.6 \mathrm{~nm})$. The knowledge about the behavior of small ions, particles and their charged fraction (air ions) during nucleation events could contribute to elucidate the role of different nucleation mechanisms.

The mobility spectrum of small ions is sensitive to the content of many trace species (gases or vapors at concentrations below 1 part per billion) in the air giving rise to certain specific ion families with characteristic mobilities (Nagato and Ogawa, 1998; Parts and Luts, 2004). The positive and negative small ions exhibit very different chemical composition (Eisele and Tanner, 1990; Beig and Brasseur, 2000; Luts and Parts, 2002). Typically positive core ions consist of hydronium $\left(\mathrm{H}_{3} \mathrm{O}^{+}\right)$, ammonium $\left(\mathrm{NH}_{4}^{+}\right)$and a variety of organic compounds (e.g. pyridine), while the dominant negative core ions besides parent species $\mathrm{NO}_{3}^{-}$and $\mathrm{HSO}_{4}^{-}$include also strong acids (nitric acid and sulfuric acid). However, the differences in physical properties of ions (mass, size and mobility) are not large, e.g. the mean mobility of negative small ions near the ground is about $13 \%$ higher than that of positive ions (Hõrrak et al., 2000).

The importance of air ions in the particle formation processes has been shown in several laboratory experiments (Ramamurthi et al., 1993; Kim et al., 1997, 1998; Hanson and Eisele, 2002; Froyd and Lovejoy, 2003a, b; Wilhelm et al., 2004). Comprehensive overviews about the charging and charge distribution on aerosol particles in a bipolar ion environment can be found in (Hoppel and Frick, 1986; Reischl et al., 1996). According to laboratory experiments and theoretical considerations, the steady state charge distribution on large aerosol particles determined by the diffusion of small ions to particles is close to the Boltzmann distribution. Corrections have been found to be necessary in the case of ultrafine particles below $100 \mathrm{~nm}$ (Fuchs and Sutugin, 1971; Hoppel and Frick, 1986; Tammet, 1991; Reischl et al., 1996). However, only few experimental studies on the subject have been carried out in the real atmosphere. So far, the problems of the bursts of intermediate ions (generation of charged nanometer aerosol particles) and of the charge distribution on freshly nucleated atmospheric nanoparticles have been briefly discussed (Hõrrak et al., 1998a, b, 2003a, b; Mäkelä et al., 2001a, 2003; Tamm et al., 2001). An extensive study of air ions and aerosol particles was recently conducted in a boreal forest at the Hyytiälä SMEAR station, Finland, during the QUEST campaign (21 March-10 April 2003) (Kulmala et al., 2004b; Laakso et al., 2004a, b). One of the important results of the QUEST 2 campaign was a charge asymmetry on intermediate air ions $(1.6-5 \mathrm{~nm})$ with an excess of negative charges and overcharging of nanometer aerosol particles (an excess of charge compared to the steady state bipolar charging probability) in the size range of 3-5 nm during weak and moderate nucleation bursts (Hõrrak et al., 2004a, b; Laakso et al., 2004a). The formation of negatively charged nanometer particles by ion-induced nucleation is in accordance with the results of laboratory experiments (Froyd and Lovejoy, 2003b; Wilhelm et al., 2004).

The objective of this work was a comparative study of positive air ions (naturally charged small ions and aerosol particles) and fine aerosol particles with the main focus on the balance between small ions and aerosols, as well as on the charging state of nanometer particles during nucleation events. Simultaneous measurements of the concentration of small ions and the size distribution of aerosol particles enable to estimate also the ionization rate of the air (or ion production rate), which is a key factor in ion-induced nucleation.

\section{Measurements}

Atmospheric aerosols and the concentration of positive air ion mobility classes were measured in a boreal forest at the Hyytiälä SMEAR II station, Finland, during the BIOFOR III campaign (31 March-29 April 1999) (Kulmala et al., 2001a; Aalto et al., 2001). The SMEAR II (Station for Measuring Forest Ecosystem-Atmosphere Relations) is located on a flat terrain at the Hyytiälä Forestry Field Station of the University of Helsinki about $220 \mathrm{~km}$ north-west of Helsinki. The station is surrounded by pine-dominated forests of middle density covering extended areas. The terrain is a subject to modest height variation (up to about $40 \mathrm{~m}$ ). The oblong Lake Kuivajärvi (141 m a.s.l.) is located about $600 \mathrm{~m}$ south-west of the station. The ground in the vicinity is igneous and metamorphic bedrock (notably granites) partly exposed or covered by a thin layer of soil (maximum up to about $2 \mathrm{~m}$ ). The nearest largest city, Tampere (204 000 inhabitants), is located about $60 \mathrm{~km}$ south-west of the station. A detailed description of the station has been given by Vesala et al. (1998) and by Hari and Kulmala (2005).

Aerosol particle size distribution was measured by means of a dual DMPS (Differential Mobility Particle Sizer) system covering the sizes of 3-500 nm (Aalto et al., 2001). The devices had a Hauke-type differential mobility analyzer (DMA), a closed-loop sheath flow arrangement and a Krypton-85 aerosol neutralizer. For large particles, an aerodynamic particle sizer (APS, TSI model 3320) was used to measure the size distribution from $0.7 \mu \mathrm{m}$ up to $20 \mu \mathrm{m}$. This instrument was located in a truck about $40 \mathrm{~m}$ from the main cottage of the SMEAR station where the DMPS system had been installed. Both instruments had sampling lines of the 2-m level inside the forest. The sample flow and sheath flow of the DMPS, as well as the sample flow of the APS were not dried. However, the size distributions of particles measured by means of both devices can be considered as "dry size distributions" due to low relative humidity inside the instruments (especially in the APS). Additional information about the accumulation mode and coarse mode 
particles in the diameter range of $0.2-32 \mu \mathrm{m}$ was obtained using in-situ optical particle counters: a Particle Measuring System's (PMS) Active Scattering Aerosol Spectrometer Probe (ASASP-300), measuring in the size range 0.2$3 \mu \mathrm{m}$, and a Classical Scattering Aerosol Spectrometer Probe (CSASP-100), covering the sizes above $1 \mu \mathrm{m}$ (Kulmala et al., 2001a; Hämeri et al., 2001). The optical counters sampled wet-ambient aerosol particles on a tower at a height of about $18 \mathrm{~m}$ above the ground and about $30 \mathrm{~m}$ from the main cottage.

In order to estimate the concentration of positive air ions in different mobility classes, four integral ion counters UT-8401 were applied (Aalto et al., 2001). Negative air ions were not measured during the BIOFOR III campaign. The ion counters were the Gerdien type aspiration counters in which the naturally charged particles (small ions and aerosol ions) deposited from the airflow by the electric field in the mobility analyzer according to their electrical mobilities and the electric current was measured by electrometer. The limiting mobilities of four ion counters, determined by the voltage, flow rate and effective capacity of the mobility analyzer, were set to $0.02,0.063,0.2$, and $0.64 \mathrm{~cm}^{2} \mathrm{~V}^{-1} \mathrm{~s}^{-1}$, respectively. Due to the nature of the integral ion counter, the concentrations of air ion mobility classes can be calculated by means of a special inversion algorithm (Tammet, 1970; Israël, 1970). The method is based on the measurements at several different limiting mobilities to determine the dependence of the ion concentration on the reciprocal of the limiting mobility (or current-voltage characteristic curve). At a certain mobility, the intercept of the characteristic curve tangent on the concentration axis yields the concentration of ions with mobilities higher than this specific mobility, and the difference between the intercepts yields the ion concentration in a mobility class. In practice, a piecewise linear approximation of the characteristic curve was used and the specific mobilities of 0.355 and $0.0355 \mathrm{~cm}^{2} \mathrm{~V}^{-1} \mathrm{~s}^{-1}$ were selected as boundaries between the mobility classes. The lower boundary of the lowest mobility class was conventionally set to $0.005 \mathrm{~cm}^{2} \mathrm{~V}^{-1} \mathrm{~s}^{-1}$ (Aalto et al., 2001). The concentrations of positive small ions (Stokes-Millikan mobility equivalent diameter less than $2.5 \mathrm{~nm}$ ) and two classes of aerosol ions - intermediate ions (or charged fine nanometer particles of 2.5-8 $\mathrm{nm}$ ) and large ions (or charged coarse nanometer particles of 8-20 nm) - were derived. Air ions were measured as naturally charged in the bipolar atmospheric air. The upper boundary of $20 \mathrm{~nm}$ cannot be exactly determined because of the contribution of charged aerosol particles of larger sizes: the larger the particle, the smaller is its contribution to signal. The sampling height of ion counters was $2 \mathrm{~m}$ above the ground; the data were recorded every $10 \mathrm{~min}$. The distance between the measurement locations of air ions and aerosols was about $450 \mathrm{~m}$. For details about the instrumentation, see (Kulmala et al., 2001a; Aalto et al., 2001).

The average temperature in the first half of April was $2.2^{\circ} \mathrm{C}$ and in the second half $7.0^{\circ} \mathrm{C}$. The depth of the snow cover was about $40 \mathrm{~cm}$ at the beginning and $20 \mathrm{~cm}$ in the middle of April; the snow cover melted quickly during the week after 15 April 1999.

\section{Theoretical background}

\subsection{The balance of ions in the atmosphere}

Small positive and negative ions are generated in the atmosphere mainly by cosmic radiation and natural radioactivity. Two concurrent processes, ion-ion recombination and adsorption of small ions by aerosol particles, are responsible for the loss of small ions. The simplified balance equation of small ions in a bipolar environment, considering equal numbers of positive and negative small ions and symmetrical charging of aerosol particles, can be written as (Hoppel and Frick, 1986)

$\frac{d n}{d t}=q-\alpha n^{2}-\beta_{\mathrm{eff}} N_{\mathrm{tot}} n$,

where $q$ is the ionization rate, $\alpha$ is the recombination coefficient, $n$ is the concentration of small ions, $N_{\text {tot }}$ is the total concentration of aerosol particles, and $\beta_{\text {eff }}$ is the effective ion-aerosol attachment coefficient for polydisperse aerosol particles. The product $\beta_{\text {eff }} N_{\text {tot }}$ characterizes the relative loss rate of small ions due to aerosols and is sometimes called "sink of ions on aerosols" or "ion sink rate" or briefly "ion sink" (Tammet et al., 2006). The time constant of the transfer to the steady state condition $(d n / d t=0)$ is about $1 \mathrm{~min}$ in the continental boundary layer air. This balance equation does not take into account the loss of small ions by ion-induced nucleation due to its complicated nature. The simplified balance equation of small ions (Eq. 1) has an analytical steady state solution:

$n=\frac{2 q}{\beta_{\text {eff }} N_{\text {tot }}+\sqrt{\beta_{\text {eff }}^{2} N_{\text {tot }}^{2}+4 \alpha q}}$.

It can also be presented in the form: $n=q \tau(q)$, where the parameter $\tau(q)$ has the dimension of time and can therefore be interpreted as the "mean lifetime" of small ions in the steady state conditions (Israël, 1970). The mean lifetime of small ions is inversely proportional to the total ion loss caused by ion-aerosol attachment and by the recombination of small ions.

The independent parameters of the balance equation have the following average values often cited in publications. The recombination coefficient $\alpha$, which depends on the nature of small ions and the properties of the environment (Israël, 1970; Hoppel and Frick, 1986), has an average value of about $1.5 \times 10^{-6} \mathrm{~cm}^{3} \mathrm{~s}^{-1}$. In continental areas, the param-

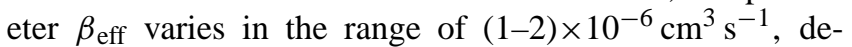
pending on the size distribution of aerosol particles (Hoppel, 1985). The average ionization rate near the ground of about 10 ion pairs $\mathrm{cm}^{-3} \mathrm{~s}^{-1}$ (caused by radioactive substances in 


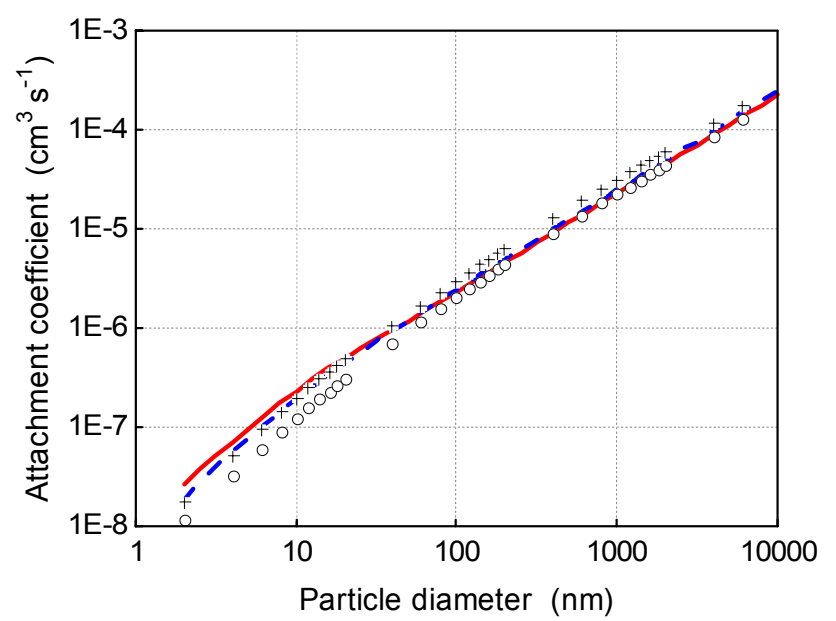

Fig. 1. Equivalent or single size ion-aerosol attachment coefficient as a function of particle size $(2 \mathrm{~nm}-10 \mu \mathrm{m})$. Solid line: model calculations (Eqs. 4-6); dashed line: approximation function (Eq. 7); plus sign (+) and open circles $(\bigcirc)$ : calculations based on Eq. (6) and the tabulated results of attachment coefficients for ions with the mobility of $1.3 \mathrm{~cm}^{2} \mathrm{~V}^{-1} \mathrm{~s}^{-1}$ and the mass of $200 \mathrm{amu}$; and of $1.8 \mathrm{~cm}^{2} \mathrm{~V}^{-1} \mathrm{~s}^{-1}$ and the mass of $100 \mathrm{amu}$, respectively (Hoppel and Frick, 1990).

the ground and in the air, and by cosmic radiation) is considered as an average for continental areas.

The sink rate of small ions on aerosols is given by the equation (Hoppel and Frick, 1986; Tammet, 1991):

$S_{a}=\beta_{\mathrm{eff}} N_{\mathrm{tot}}=\int_{d} \sum_{i=-\infty}^{\infty} \beta_{i}(d) p_{i}(d) N(d) d d$,

were $\beta_{i}(d)$ is the ion-aerosol attachment coefficient between small positive (or negative) ions and particles with diameter $d$ and with $i$ (or $-i$ ) elementary charges, $p_{i}(d)$ is the probability of carrying $i$ elementary charges on a particle and $N(d)$ is the size distribution of aerosol particles.

The attachment of small ions to aerosol particles gives rise to a size-dependent statistical charge distribution on the aerosol particles (Hoppel and Frick, 1986; Reischl et al., 1996). The time in which the aerosol particle population approaches charge equilibrium depends on the collision rate between small ions and aerosol particles, and also on the particle formation mechanism (e.g. homogeneous nucleation, ioninduced nucleation). Considering typical atmospheric conditions and initially neutral ultrafine aerosol particles, the time required to reach charge equilibrium is typically in the range of about $0.5-1 \mathrm{~h}$ (Hoppel, 1985). For rural areas, away from direct sources of aerosol particles, the assumption of charge equilibrium is presumed to be fairly good. However, the charge distribution on freshly nucleated nanometer particles needs further study.

\subsection{Calculation of the ion sink rate}

The effect of atmospheric aerosols on the small ion concentration was estimated applying a simplified model of bipolar diffusion charging of aerosols (by small ions) and assuming the steady state conditions and symmetrical charging (Tammet, 1991; Hõrrak et al., 1998b). The calculation of the ion sink rate Eq. (3) is based on the model of ion-aerosol attachment (Hoppel and Frick, 1986; 1990). The charging probability $p_{i}(d)$ for the steady state is calculated using the algorithm given by Tammet (1991) with improvements described in Hõrrak et al. (1998b). The model of charge distribution is based on the expression for the attachment coefficient of a small ion to an aerosol particle:

$$
\beta_{i}(d)=\frac{2 \pi d k T Z}{e} \frac{x}{\exp (x)-1} \sqrt{1-\frac{2}{2+i(i-1)+d /(10 \mathrm{~nm})}},
$$

where $Z$ is the mean mobility of small ions, $x=i e^{2} /\left(2 \pi d \varepsilon_{o} k T\right), \varepsilon_{o}$ is the electric constant, $k$ is the Boltzmann constant, and $T$ is the temperature. The Eq. (4) approximates the tabulated results of Hoppel and Frick (1990) and is also in accordance with the experimental data of charging probabilities of nanometer aerosol particles (Reischl et al., 1996).

The function $p_{i}(d)$ is defined by the equation:

$p_{i}(d)=\frac{N_{i}(d)}{N(d)}=\frac{N_{i}(d)}{N_{o}(d)+2 \cdot \sum_{j=1}^{\infty} N_{j}(d)}$,

where $N_{i}(d)$ or $N_{j}(d)$ is the fraction concentration of particles at the diameter $d$ with $i$ or $j$ elementary charges, $N(d)$ is the total concentration and $N_{0}(d)$ is the concentration of neutral particles at the diameter $d$. In the steady state $N_{i}(d) / N_{0}(d)=\prod_{j=1}^{i} \beta_{j-1}(d) / \beta_{-j}(d)$. The equivalent, or the single size ion-aerosol attachment coefficient

$w(d)=\sum_{i=-\infty}^{\infty} \beta_{i}(d) p_{i}(d)$

in Eq. (3) is almost proportional to the particle diameter and, therefore, the ion sink $S_{a}$ can be interpreted as the diameter concentration of aerosol particles, or the sum of aerosol particle diameters per unit volume (Hoppel and Frick, 1986; Tammet, 1991). A simple approximation function originates from Tammet (1991):

$w(d)=\sqrt{\frac{d-1 \mathrm{~nm}}{d+5 \mathrm{~nm}}} \frac{d}{40 \mathrm{~nm}} 10^{-6}$,

where the particle diameter $d$ is in nanometers (nm) and $w(d)$ is in $\mathrm{cm}^{3} \mathrm{~s}^{-1}$. Equation (7) was improved compared to (Tammet 1991): the square root was added, which provides a better agreement with exact calculations by means of Eqs. (4), 
Table 1. Descriptive statistics of the positive small ion concentration $(n)$, effective attachment coefficient $\left(\beta_{\text {eff }}\right)$, the sink of small ions on aerosol particles of $3-500 \mathrm{~nm}\left(S_{a}\right)$, ion loss due to the recombination of small ions $(\alpha \cdot n)$, the ionisation rate $(q)$, the total concentration of aerosol particles $\left(N_{\text {tot }}\right)$ and the ratio of ion loss due to the recombination to total ion loss due to particles (last row). 31 March-29 April 1999, Hyytiälä.

a) Nucleation event days (number of measurements 1813).

\begin{tabular}{llllllllll}
\hline & Mean & Median & Min & Max & $\begin{array}{l}\text { Lower } \\
\text { Quartile }\end{array}$ & $\begin{array}{l}\text { Upper } \\
\text { Quartile }\end{array}$ & $\begin{array}{l}\text { Percentile } \\
10\end{array}$ & $\begin{array}{l}\text { Percentile } \\
90\end{array}$ & Std.Dev. \\
\hline$n, \mathrm{~cm}^{-3}$ & 530 & 510 & 110 & 1180 & 430 & 610 & 360 & 730 & 150 \\
$\beta_{\text {eff }}, 10^{-6} \mathrm{~cm}^{3} \mathrm{~s}^{-1}$ & 1.3 & 1.2 & 0.20 & 3.3 & 0.63 & 1.8 & 0.41 & 2.4 & 0.73 \\
$S_{a}, 10^{-3} \mathrm{~s}^{-1}$ & 4.2 & 3.9 & 0.39 & 12 & 2.7 & 5.4 & 1.7 & 6.7 & 2.0 \\
$\alpha \cdot n, 10^{-3} \mathrm{~s}^{-1}$ & 0.80 & 0.77 & 0.17 & 1.8 & 0.65 & 0.92 & 0.55 & 1.1 & 0.22 \\
$q, \mathrm{~cm}^{-3} \mathrm{~s}^{-1}$ & 2.5 & 2.3 & 0.8 & 7.6 & 1.8 & 2.9 & 1.5 & 3.7 & 0.94 \\
$N_{\text {tot }}$ & 4070 & 3470 & 590 & 18980 & 2280 & 5340 & 1420 & 7360 & 2580 \\
$\alpha \cdot n /\left(\alpha \cdot n+S_{a}\right)$ & 0.20 & 0.16 & 0.024 & 0.75 & 0.11 & 0.26 & 0.076 & 0.35 & 0.13 \\
\hline
\end{tabular}

b) Non-event days (number of measurements 1754).

\begin{tabular}{llllllllll}
\hline & Mean & Median & Min & Max & $\begin{array}{l}\text { Lower } \\
\text { Quartile }\end{array}$ & $\begin{array}{l}\text { Upper } \\
\text { Quartile }\end{array}$ & $\begin{array}{l}\text { Percentile } \\
10\end{array}$ & $\begin{array}{l}\text { Percentile } \\
90\end{array}$ & Std.Dev. \\
\hline$n, \mathrm{~cm}^{-3}$ & 420 & 410 & 120 & 1180 & 280 & 540 & 220 & 660 & 180 \\
$\beta_{\mathrm{eff}}, 10^{-6} \mathrm{~cm}^{3} \mathrm{~s}^{-1}$ & 2.2 & 2.2 & 0.63 & 3.9 & 1.6 & 2.9 & 1.1 & 3.2 & 0.74 \\
$S_{a}, 10^{-3} \mathrm{~s}^{-1}$ & 7.6 & 5.4 & 1.2 & 59 & 4.1 & 8.4 & 3.4 & 16 & 6.4 \\
$\alpha \cdot n, 10^{-3} \mathrm{~s}^{-1}$ & 0.64 & 0.61 & 0.18 & 1.8 & 0.42 & 0.81 & 0.33 & 0.99 & 0.27 \\
$q, \mathrm{~cm}^{-3} \mathrm{~s}^{-1}$ & 3.0 & 2.8 & 0.6 & 14 & 1.9 & 3.8 & 1.4 & 4.9 & 1.6 \\
$N_{\mathrm{tot}}$ & 3520 & 2910 & 540 & 25450 & 2050 & 4340 & 1390 & 5830 & 2620 \\
$\alpha \cdot n /\left(\alpha \cdot n+S_{a}\right)$ & 0.11 & 0.10 & 0.005 & 0.48 & 0.050 & 0.15 & 0.022 & 0.20 & 0.073 \\
\hline
\end{tabular}

(5) and (6). The dependence of the single size ion-aerosol attachment coefficient on the particles of different sizes ( $2 \mathrm{~nm}-$ $10 \mu \mathrm{m})$ is shown in Fig. 1. The mean mobility of positive and negative small ions of $1.45 \mathrm{~cm}^{2} \mathrm{~V}^{-1} \mathrm{~s}^{-1}$, standard temperature $\left(20^{\circ} \mathrm{C}\right)$ and air pressure $(1013 \mathrm{mb})$ have been used in these calculations.

The small ion sink on aerosols $S_{a}$ is found by integrating over the size distribution of aerosol particles of 3-500 nm measured by means of the dual DMPS system. The effect of large particles above $500 \mathrm{~nm}$ was studied using the data of the Aerodynamic Particle Sizer (APS) and optical particles counters. The particle size distributions in the diameter range of $0.72-20 \mu \mathrm{m}$, measured with the APS, were converted to the mobility diameter by dividing the aerodynamic diameter by the square root of the estimated particle density of $1.9 \mathrm{~g} \mathrm{~cm}^{-3}$ (Aalto et al., 2001). The ion sink rate is closely correlated with the condensation sink rate (condensation rate of vapors on aerosol particles) (Kulmala et al., 2001b) because both factors are mainly depending on the diameter concentration of aerosol particles (first moment of the size distribution).

\section{Results and discussion}

\subsection{Statistical characterization of small air ions and ion loss}

Statistical characteristics of the positive small (cluster) ion concentration, the sink rate of small ions on aerosol particles of 3-500 nm measured by the DMPS, as well as the factors of the small ion balance Eq. (2) are presented in Table 1, separately for the nucleation event days and non-event days. The days have been classified as "nucleation event days" or "non-event days" according to the occurrence of new particle formation followed by the particle size distribution measurements. The classification given in Kulmala et al. (2001a) was used in the present study with one exception: the first half of 21 April, when polluted air masses were present, was excluded from the list of nucleation event days.

Considering all the measurements, the small ion sink on aerosols $S_{a}$ varied in the range of $3.9 \times 10^{-4}-5.8 \times 10^{-2} \mathrm{~s}^{-1}$, commonly $1 \times 10^{-3}-1.2 \times 10^{-2} \mathrm{~s}^{-1}$. The smallest values were recorded after the inflow of clean maritime air masses, while the highest values correspond to the polluted continental air masses, when the accumulation mode aerosol particles are mainly responsible for the ion sink. During the nucleation event days (13 days) the average sink rate of ions was about 1.8 times smaller compared to non-event days, and the mean concentration of small ions was higher: $530 \mathrm{~cm}^{-3}$ versus 


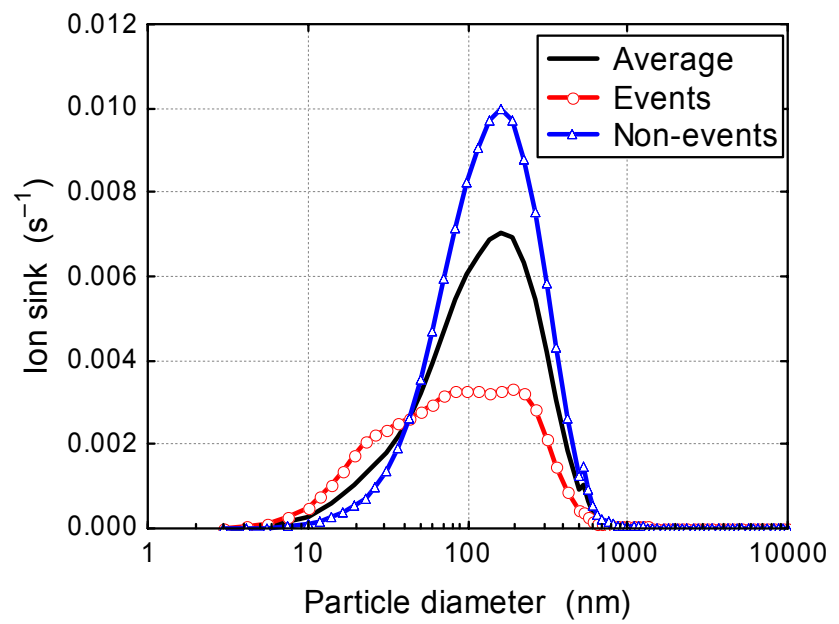

Fig. 2. Ion sink rate as a function of particle size (factor $\mathrm{dN} / \mathrm{d} \log (\mathrm{d}) \cdot \mathrm{w}(\mathrm{d}))$ for the nucleation event days, non-event days and the average of the period of 31 March-29 April 1999. Hyytiälä station.

$424 \mathrm{~cm}^{-3}$, respectively. The highest concentrations of small ions up to about $1200 \mathrm{~cm}^{-3}$ were recorded during nighttime calms. The high concentrations were probably caused by the accumulation of radon near the ground during temperature inversions (Porstendörfer, 1994; Penttinen et al., 2003), which can significantly increase the ionization rate of the air. In the nucleation event days, the average diurnal variation of the small ion concentration displayed the maximum of about $625 \mathrm{~cm}^{-3}$ during nighttime at 22:00-23:00 LST, and the minimum of $460 \mathrm{~cm}^{-3}$ in the morning at 07:00-08:00 LST. The secondary maximum of $580 \mathrm{~cm}^{-3}$, which appeared at noon (11:30 LST), was correlated with the minimum in the ion sink rate of $2.6 \times 10^{-3} \mathrm{~s}^{-1}$ (the maximum of ion sink rate of $5.2 \times 10^{-3} \mathrm{~s}^{-1}$ appeared at $24 \mathrm{LST}$ ). The secondary maximum of small ions took place before the intensive generation of nanometer particles; it preceded the maximum of the average diurnal variation of $3 \mathrm{~nm}$ particles by about $1 \mathrm{~h}$. In general, the small ions measured at Hyytiälä showed similar regularities as at Tahkuse, but the concentrations were about two times higher than at the Tahkuse Observatory, Estonia (Hõrrak et al., 2000, 2003b).

Extra information about negative small ions was gained from the mobility distribution measurements in the range of $0.5-3.2 \mathrm{~cm}^{2} \mathrm{~V}^{-1} \mathrm{~s}^{-1}$ at the same place during the QUEST 2 campaign in spring 2003. The average concentration of negative small ions and their standard deviation was $575 \pm 114 \mathrm{~cm}^{-3}$. This is about 1.14 times lower than the concentration of positive cluster ions $\left(655 \pm 118 \mathrm{~cm}^{-3}\right)$ at Hyytiälä in early spring (Hirsikko et al., 2005). The concentrations of positive and negative ions were closely correlated; the correlation coefficient was $93.6 \%$. The mean mobilities of negative and positive small ions were $1.69 \mathrm{~cm}^{2} \mathrm{~V}^{-1} \mathrm{~s}^{-1}$ and $1.45 \mathrm{~cm}^{2} \mathrm{~V}^{-1} \mathrm{~s}^{-1}$, respectively (Laakso et al., 2004b), and the correlation between the quantities was about $60 \%$.
It is worth to point out that during the BIOFOR III campaign at the Hyytiälä station, the loss of small ions due to ion-ion recombination (assuming the recombination coefficient $1.5 \times 10^{-6} \mathrm{~cm}^{3} \mathrm{~s}^{-1}$ ) was about $16 \%$ of the total ion loss due to small ion recombination and attachment to the aerosol particles, in average. Typically, it is less than 5\% for continental areas (Tammet, 1991). In the case of very clean air, e.g. after the Arctic cold air advection from the Northern Atlantic, the small ion recombination was responsible for about $70 \%$ of ion losses (Table 1). Here we neglected the effect of ion-induced nucleation on the loss of small ions. We also assumed equal concentrations of positive and negative small air ions; in general, the ratio of positive to negative ions is about 1.12 (Hõrrak et al., 2000). The peak concentrations of small ions at Hyytiälä, recorded in the very clean air (about $800 \mathrm{~cm}^{-3}$ ), are still considerably smaller than the concentrations (up to $1200 \mathrm{~cm}^{-3}$ ) recorded during nocturnal calms (radon accumulation effect).

The sink of small ions at the Hyytiälä station was mainly determined by the concentration of particles in the size range of 3-500 nm measured by the DMPS; the contribution of larger particles measured by the APS (mobility equivalent diameter $0.52-15 \mu \mathrm{m}$ ) was about two orders of magnitude smaller (see Fig. 2). For example, during the nucleation event days (non-event days), an average value of an ion sink rate measured by the APS was $4.88 \times 10^{-5} \mathrm{~s}^{-1}\left(11.47 \times 10^{-5} \mathrm{~s}^{-1}\right)$ and maximum was $14.5 \times 10^{-5} \mathrm{~s}^{-1}\left(49.6 \times 10^{-5} \mathrm{~s}^{-1}\right)$, respectively. The percentage contribution of particles in the size range of the APS was about $1.5 \%$ in average, and always less than $8 \%$. Therefore, if high accuracy is not essential when calculating the ion sink rate, then we can take into account only the DMPS measurements. However, the estimated ion sink rates are probably to a certain extent underestimated because we did not take into account the hygroscopic growth of particle size due the effect of ambient humidity. During the BIOFOR campaign, Hämeri et al. (2001) studied the hygroscopic growth of aerosol particles in the dry particle diameter range of $0.01-2 \mu \mathrm{m}$ when taken from the dry state (relative humidity $\mathrm{RH}<5 \%$ ) to $\mathrm{RH}=90 \%$. The growth factors ranged between 1.0 and 1.6 considering particles of different sizes, and a clear diurnal variation of the growth factors of nucleation, Aitken and accumulation mode particles was found during nucleation event days.

The effective attachment coefficient ( $\left.\beta_{\text {eff }}\right)$, which is proportional to the mean diameter of aerosol particles, varied in the range of $2 \times 10^{-7}-3.85 \times 10^{-6} \mathrm{~cm}^{3} \mathrm{~s}^{-1}$. These changes in the remote environment are affected by the longrange transport of aerosol pollutants and/or clean air advection, by the transformation of aerosol size distribution due to the evolution of boundary layer and new particle generation (Nilsson et al., 2001a, b). During the nucleation burst days the effective attachment coefficient showed a considerable diurnal variation; on the average, it varied from about $6 \times 10^{-7} \mathrm{~cm}^{3} \mathrm{~s}^{-1}$ up to $1.8 \times 10^{-6} \mathrm{~cm}^{3} \mathrm{~s}^{-1}$, displaying a nighttime maximum at about 04:00-05:00 LST 
and a minimum in the afternoon at 16:00 LST. During the peak time of nanometer particle generation by photochemical nucleation around noon, the effective attachment coefficient was almost always less than $6 \times 10^{-7} \mathrm{~cm}^{3} \mathrm{~s}^{-1}$. The effective attachment coefficients found by Hoppel (1985) at the Naval Research Laboratory in urban Washington, D.C. were $1.15 \times 10^{-6}$ and $1.97 \times 10^{-6} \mathrm{~cm}^{3} \mathrm{~s}^{-1}$, and the ion sink rates calculated from those measurements were $1.6 \times 10^{-2}$ and $4.64 \times 10^{-2} \mathrm{~s}^{-1}$ for the periods of good and poor visibility, respectively. Measurements in the marine environment near the east coast of the United States revealed the attachment coefficients from $0.89 \times 10^{-6} \mathrm{~cm}^{3} \mathrm{~s}^{-1}$ up to $2.63 \times 10^{-6} \mathrm{~cm}^{3} \mathrm{~s}^{-1}$ and in the remote Atlantic as high as $3.18 \times 10^{-6} \mathrm{~cm}^{3} \mathrm{~s}^{-1}$. The corresponding ion sink rates were in the range of $1.8 \times 10^{-2}-2.4 \times 10^{-2} \mathrm{~s}^{-1}$ and $6.46 \times 10^{-4} \mathrm{~s}^{-1}$, respectively. The effective attachment coefficients in considerably different environments are comparable with each other and with average values found in the boreal forest at Hyytiälä. The ion sink influenced by local air pollution, anthropogenic and natural sources of aerosols is a subject to considerable differences.

The average ionization rate of about 2.8 ion pairs $\mathrm{cm}^{-3} \mathrm{~s}^{-1}$, calculated from the balance Eq. (1) considering the steady state conditions, is too small for continental stations. It is probably underestimated by a factor of 2 . The average ionization rate at $1 \mathrm{~m}$ height from the ground about 10 ion pairs $\mathrm{cm}^{-3} \mathrm{~s}^{-1}$ is considered as an average for continental areas (Israël, 1970, 1973; Chalmers, 1967). Three main ionizing agents (factors) have the following contribution: the ionization rate caused by radioactive substances in the ground is about 4.6 ion pairs $\mathrm{cm}^{-3} \mathrm{~s}^{-1}$ and in the air (radon, radioactive aerosol) 4 ion pairs $\mathrm{cm}^{-3} \mathrm{~s}^{-1}$, and by cosmic radiation 1.5-1.8 ion pairs $\mathrm{cm}^{-3} \mathrm{~s}^{-1}$. Considering different locations, the ionization rate could exhibit considerable variations depending on the content of radioactive substances in the ground, on the soil properties and due to local orography. The measurements below $1 \mathrm{~m}$ strongly depend on the ionization profile. The temporal variations in the ionization rate (annual and diurnal variation) are mostly due to variations in radon and thoron concentration in the air (Porstendörfer, 1994; Hoppel et al., 1986). Our estimates of the ionization rate did not take into account the loss of small ions by the deposition on the coniferous forest, which could affect the measurements at the Hyytiälä station, as well as the differences in the sizes of wet ambient particles and those sampled by the DMPS. Presumably, the uncertainties of ion loss caused by these factors can explain the small values of ionization rate. The exceptionally high ionization rates found on 21 April with the nighttime maximum of 14.6 ion pairs $\mathrm{cm}^{-3} \mathrm{~s}^{-1}$ (Table $1 \mathrm{~b}$ ) are probably the artifacts caused by local air pollution, which did not affect the ion measurements. The most reasonable maximum value of the ionization rate estimated from the density distribution (excluding data of 21 April) is equal to that found for the nucleation event days, about 7.6 ion pairs $\mathrm{cm}^{-3} \mathrm{~s}^{-1}$. The average diurnal variation of the ionization rate displayed a moderate variation with the nighttime maximum of about 3.4 ion pairs $\mathrm{cm}^{-3} \mathrm{~s}^{-1}$ and the minimum of 2 ion pairs $\mathrm{cm}^{-3} \mathrm{~s}^{-1}$ in the afternoon.

Laakso et al. (2004a) applied the same approach to the calculation of the ionization rate based on the measurements of the QUEST 2 campaign at the Hyytiälä station in spring 2003. The effect of the hygroscopic growth of the measured dry aerosol particle size distributions due to ambient humidity was also taken into account, but the average ionization rate stayed at a low value of 2.6 ion pairs $\mathrm{cm}^{-3} \mathrm{~s}^{-1}$.

The measurements at Hyytiälä show that the atmosphere always contains small air ions that can act as condensation centers (of about $1 \mathrm{~nm}$ size) in the nucleation process. During intensive generation of nanometer aerosol particles the concentration of small ions was in the range of $380-780 \mathrm{~cm}^{-3}$, considering different event days. Therefore, when the homogeneous nucleation of new aerosol particles takes place in the atmosphere, it should be accompanied by ion-induced nucleation (see e.g. Hoppel et al., 1994; Raes and Van Dingenen, 1992). To maintain the small ion population, the production rate of aerosols by ion-induced nucleation at the Hyytiälä station should be limited by the ionization rate (about 4-6 ion pairs $\mathrm{cm}^{-3} \mathrm{~s}^{-1}$ ) (Laakso et al., 2004a).

\subsection{Correlation between the concentration of small ions and ion sink rate}

The correlation between small ion concentration and the sink rate of small ions on aerosol particles of the sizes of 3$500 \mathrm{~nm}$ is depicted in Fig. 3. The overall correlation is weak owing to the nighttime calms and weak wind, and due to high humidity periods (probably fog events), when the concentration of small ions varied independently of the ion sink. The fog is known to affect the conductivity of atmospheric air, reducing the concentration of small ions (Dolezalek, 1963; Hoppel et al., 1986). Contrary to that, the nighttime calms and weak wind favor the accumulation of radon near the ground, resulting in an increase in the ionization rate and, therefore, in the concentration of small ions up to about $1200 \mathrm{~cm}^{-3}$. Unfortunately, the radon concentration was not measured during the BIOFOR campaign. The accumulation of radon is confirmed by the measurements carried out at Hyytiälä during 2000-2003 (Penttinen et al., 2003). An alternative explanation of the occurrence of nighttime high concentrations proceeds from the hypothesis that the deposition rate of small ions on the coniferous forest is reduced in the case of weak wind and stable boundary layer, while the turbulent mixing can effectively enhance the deposition (Tammet and Kimmel, 1998; Tammet et al., 2001).

The fog events were identified comparing the data of the aerodynamic particle sizer (APS) and the optical aerosol spectrometer probes (ASASP-300 and CSASP-100). The APS measures dry aerosol size distribution, while the optical probes sample wet-ambient particles in-situ at a high flow rate, thus providing measurements of hydrated aerosol size 

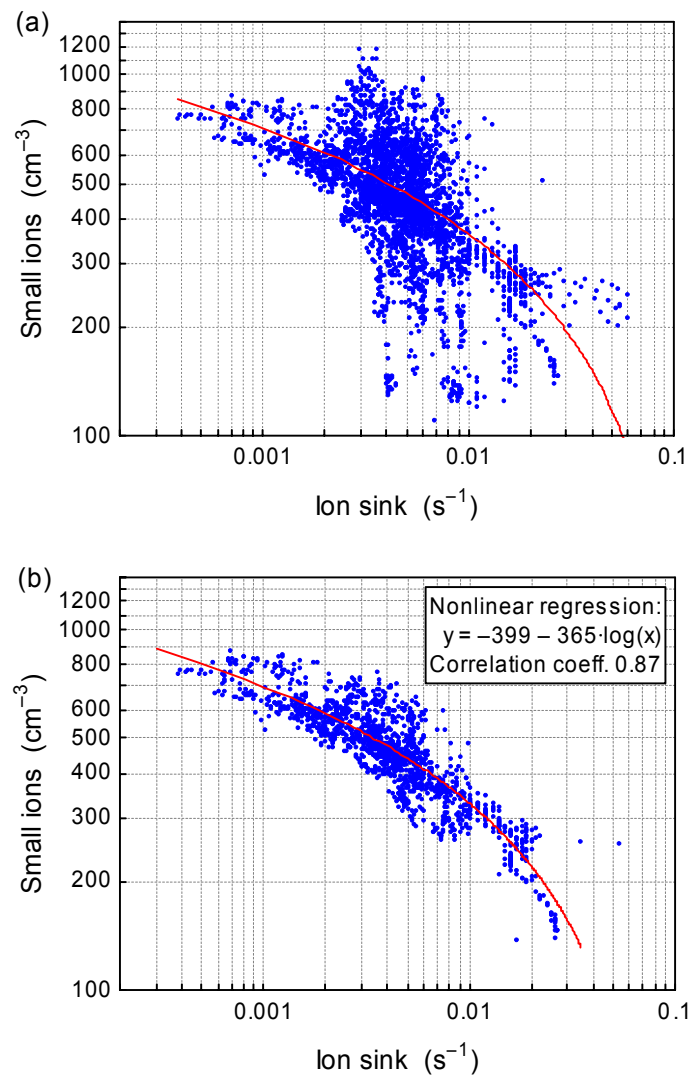

Fig. 3. Scatterplot of the concentration of positive small air ions $(n)$ versus ion sink $\left(S_{a}\right)$ on aerosol particles $(3-500 \mathrm{~nm})$ and a logarithmic regression line. (a) all the data, (b) selected data when no fog was recorded, relative humidity is less than $95 \%$, and the wind speed is higher than $0.6 \mathrm{~m} \mathrm{~s}^{-1}$. 31 March-29 April 1999, Hyytiälä station.

distributions affected by the ambient relative humidity. During high humidity (above 99\%), the size spectra were often completely different above the diameter of $0.5 \mu \mathrm{m}$, probably due to the presence of fog droplets, which are supposed to reside in the size range of $2-40 \mu \mathrm{m}$. We found an indication of fog during the nighttime and/or early morning on 1 , 2, 7, 15, 17 and 23 April. The effect of five fog events, when the ion counters were working properly and providing correct results, can be clearly seen in Fig. 3a. The concentration of small ions had undergone a considerable decrease (deviation from the regression line), reaching values less than about $150 \mathrm{~cm}^{-3}$. These situations were correlated with fog events.

Another factor that could affect the concentration of small ions is precipitation (snow, sleet, rain). Precipitation can decrease the ionization rate due to the attenuation of gamma and beta radiation from the ground and due to the block of radon exhalation by the wet ground surface. Contrary to that, precipitation can also cause an increase in the ionization rate close to the ground due to the wet deposition of short-lived radioactive radon daughters attached to aerosol particles (Hatakka et al., 1998). The effect of precipitation (snow, sleet, rain) was studied, but no clear direct or indirect effect on the concentration of small ions was found.

To find out a clear relationship between the concentration of small ions and the ion sink, we excluded the presumable fog events and also the hours of high humidity (more than $95 \%$ ), as well as the periods of weak wind (wind speed less than $0.6 \mathrm{~m} \mathrm{~s}^{-1}$ ) from the dataset. The results are depicted in Fig. 3b. In the case of the smallest sink rate of ions of $3.9 \times 10^{-4} \mathrm{~s}^{-1}$, recorded after the inflow of clean maritime air masses from the North Atlantic (Mäkelä et al., 2001b), the concentration of small ions rose up to $800 \mathrm{~cm}^{-3}$, while during the polluted continental air masses (coming from Russia over St. Petersburg) with a considerably higher ion sink rate of $2.6 \times 10^{-2} \mathrm{~s}^{-1}$ the small ion concentration was diminishing down to $150 \mathrm{~cm}^{-3}$.

In accordance with the balance equation of small ions (2), if the ion sink rate is below about $10^{-3} \mathrm{~s}^{-1}$, the small ion concentration becomes nearly independent of that of aerosol particles approaching its limit in the case of aerosol free atmosphere. The concentration limits are about 1030, 1830 or $2580 \mathrm{~cm}^{-3}$ if the ionization rate is $1.6,5$ or 10 ion pairs $\mathrm{cm}^{-3} \mathrm{~s}^{-1}$, respectively. The concentration limit of $1030 \mathrm{~cm}^{-3}$ best suits our data, but the regression line in Fig. $3 b$ is still far from the relationship predicted by Eq. (2), displaying significantly higher ion concentrations considering the ion sink rates above $10^{-3} \mathrm{~s}^{-1}$. The fact that the ionization rate of the air depends on the content of radioactive aerosols might only partially explain the discrepancy.

The correlation between the small ion concentration and the ion sink rate was stronger during the nucleation event days, because there were no fog events (except one, on 2 April) and relative humidity was considerably lower (average $62 \%$ ), compared with the non-event days (average $82 \%$ ). If to take into account only the hours when the atmospheric boundary layer was well mixed (wind speed higher than $1 \mathrm{~m} \mathrm{~s}^{-1}$ ), then the nonlinear correlation coefficient was $-92 \%$.

\subsection{Estimation of the ionization rate}

As discussed in the Sect. 4.1, the ionization rate derived from the balance equation of small ions (Eq. 1) has unlikely low values for continental stations: the average is about 2.8 ion pairs $\mathrm{cm}^{-3} \mathrm{~s}^{-1}$. This value is close to the ionization rate measured in the marine environment, which showed the variation from 1.5 to 2.9 ion pairs $\mathrm{cm}^{-3} \mathrm{~s}^{-1}$ within different latitudes (Hensen and van der Hage, 1994). The ionizing radiation measurements in Hyytiälä in early spring 2003 gave the mean value of 4.5 ion pairs $\mathrm{cm}^{-3} \mathrm{~s}^{-1}$ (Laakso et al., 2004a). Such a large difference of about 1.6 times cannot be explained simply by measurement uncertainties. We assume that the balance equation is valid in general, but the ion loss has been underestimated. However, the concentration of small ions $(n)$ and the ion sink $\left(S_{a}\right)$ were closely 
correlated (see Fig. 3b). Therefore, we are looking for a constant extra ion loss, the addition of which can solve the discrepancy between the experimental data and the results derived from the balance equation. We applied a method of least squares to find out statistically grounded estimates of the free parameters of the balance equation: the ionization rate and a constant term of ion loss. To minimize the influence of local effects and fog events on the results, the periods of well-mixed atmospheric boundary layer were selected (wind speed $>1 \mathrm{~m} \mathrm{~s}^{-1}$, relative humidity $<95 \%$ ) for the data analysis. The results of the regression analysis are depicted in Fig. 4. The statistical estimate of the ionization rate is 4.8 ion pairs $\mathrm{cm}^{-3} \mathrm{~s}^{-1}$ (with standard error of estimate 0.11 ion pairs $\mathrm{cm}^{-3} \mathrm{~s}^{-1}$ ) and that of the additional constant ion loss is $5.2 \times 10^{-3} \mathrm{~s}^{-1}$ (standard error $2.0 \times 10^{-4} \mathrm{~s}^{-1}$ ). Thus, the improved balance equation of small ions in steady state conditions can be written as

$q=\alpha n^{2}+\left(S_{a}+S_{e}\right) n$

This extra ion loss $\left(S_{e}\right)$, which is approximately equal to the mean rate of ion sink on aerosol particles of the sizes of 3$500 \mathrm{~nm}$, could be caused by the enhanced deposition of small ions on the coniferous forest (Tammet et al., 2006). The ionization rate of 4.8 ion pairs $\mathrm{cm}^{-3} \mathrm{~s}^{-1}$ is typical for the continental stations of high latitude during the wintertime when the snow cover is present. The same results were obtained when the hours with the wind speed higher than $0.6 \mathrm{~m} \mathrm{~s}^{-1}$ and relative humidity less than $95 \%$ were taken into account.

The estimated ionization rate of 4.8 ion pairs $\mathrm{cm}^{-3} \mathrm{~s}^{-1}$ fairly coincides with the value of 4.5 ion pairs $\mathrm{cm}^{-3} \mathrm{~s}^{-1}$ calculated for the same place from the external radiation and radon concentration measurements carried out during the QUEST 2 measurement campaign in spring 2003 (Laakso et al., 2004a). Based on the results of the regression analysis, we can conclude that the ionization rate in Table 1 is systematically underestimated by about 2 ion pairs $\mathrm{cm}^{-3} \mathrm{~s}^{-1}$ and the ion loss of about $5.2 \times 10^{-3} \mathrm{~s}^{-1}$. Also, the extra ion loss reduces significantly (up to about 4 times) the percentage of small ion loss due to the ion-ion recombination given in Table 1 . The corrected mean value of the percentage contribution is about $7 \%$ and the maximum is $18 \%$.

\subsection{Charging state of nanometer aerosol particles}

Simultaneous measurements of the concentrations of aerosol particles and naturally charged particles (air ions) in the atmosphere in the same size range enable to estimate the charged fraction or charging probability of particles. Considering the accuracy of nanometer particle measurements, it is possible to study the process only during the nucleation event days, when the enhanced concentrations of nanometer particles (3-10 nm) up to about $12000 \mathrm{~cm}^{-3}$ (bursts) are observable in the size spectra in fine weather conditions during the daytime.

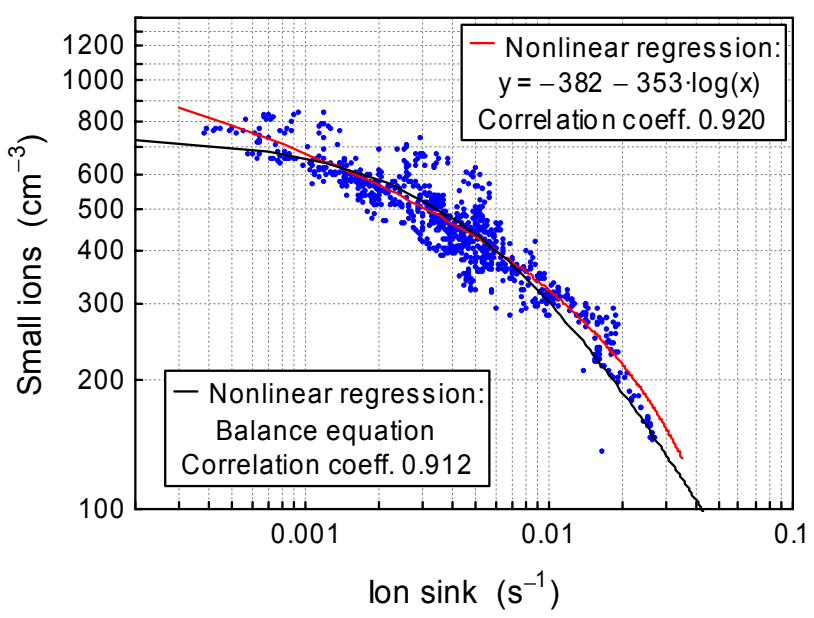

Fig. 4. Scatterplot of the concentration of positive small air ions $(n)$ versus ion sink $\left(S_{a}\right)$ on aerosol particles $(3-500 \mathrm{~nm})$. Comparison of experimental data and the results derived from the balance equation assuming the ionization rate of 4.8 ion pairs $\mathrm{cm}^{-3} \mathrm{~s}^{-1}$, an extra ion loss of $0.0052 \mathrm{~s}^{-1}$ and the recombination coefficient of $1.5 \times 10^{-6} \mathrm{~cm}^{3} \mathrm{~s}^{-1}$. Selected data: relative humidity $<95 \%$, wind speed $>1 \mathrm{~m} \mathrm{~s}^{-1}$. 31 March-29 April 1999, Hyytiälä station.

To find the aerosol particle concentration in the size range coinciding with that of intermediate ions $m(2.5-8 \mathrm{~nm})$, we extrapolated the size distribution below $3 \mathrm{~nm}$. The upper boundary of the large ions $N(8-20 \mathrm{~nm})$ is not exactly determined because of the applied method of air ion measurements by means of integral ion counters. Despite all, the analysis of the correlation between the concentrations of nanometer aerosol particles and their charged fraction (positive air ions) showed a good qualitative consistency in the case of the nucleation event days (Fig. 5). During the nonevent days, the concentrations of particles and air ions in the size class of $2.5-8 \mathrm{~nm}$ were close to low background (see Table 2), and the correlation was poor in general, while the particles and ions in the size class of $8-20 \mathrm{~nm}$ could show considerably higher concentrations and, therefore, also a stronger correlation (e.g. on 9 April, the correlation coefficient was $95 \%$ ).

During the nucleation event days, the enhancement of particle concentration in the size range of $2.5-8 \mathrm{~nm}$ precedes that in the size range of $8-20 \mathrm{~nm}$ as a consequence of particle growth toward large sizes. The average diurnal variation in the concentration of particles (and air ions) in the size class of $2.5-8 \mathrm{~nm}$ showed the maximum of $1910 \mathrm{~cm}^{-3}$ $\left(120 \mathrm{~cm}^{-3}\right)$ at noon (12:00-13:00 LST), and in the size class of $8-20 \mathrm{~nm}$ about $3600 \mathrm{~cm}^{-3}\left(170 \mathrm{~cm}^{-3}\right)$ four hours later at 16:00-17:00 LST. A wide minimum of particles (and ions) in the size class of $2.5-8 \mathrm{~nm}$ about $20-50 \mathrm{~cm}^{-3}\left(45-50 \mathrm{~cm}^{-3}\right)$ was recorded during the nighttime and early morning hours at 22:00-07:00 LST; the minimum of larger particles (and ions) about $300-400 \mathrm{~cm}^{-3}\left(45-50 \mathrm{~cm}^{-3}\right)$ took place in the early morning at 04:00-09:00 LST. 
Table 2. Descriptive statistics of the concentration of positive aerosol ions: intermediate ions $(m)$, large ions $(N)$, and the corresponding classes of nanometer aerosol particles $(A)$ of the sizes of $2.5-8 \mathrm{~nm}$ and $8-20 \mathrm{~nm}$ during the nucleation event days/non-event days. The number of measurements during the nucleation event days is 1506 and on the non-event days 1503. 31 March-29 April 1999, Hyytiälä.

\begin{tabular}{llllllllll}
\hline & Mean & Median & Min* & Max & $\begin{array}{l}\text { Lower } \\
\text { Quartile }\end{array}$ & $\begin{array}{l}\text { Upper } \\
\text { Quartile }\end{array}$ & $\begin{array}{l}\text { Percentile } \\
10\end{array}$ & $\begin{array}{l}\text { Percentile } \\
90\end{array}$ & Std.Dev. \\
\hline$m, \mathrm{~cm}^{-3}$ & $67 / 36$ & $57 / 33$ & $0 / 0$ & $428 / 130$ & $38 / 21$ & $81 / 48$ & $27 / 11$ & $125 / 63$ & $45 / 21$ \\
$N, \mathrm{~cm}^{-3}$ & $96 / 50$ & $77 / 47$ & $0 / 0$ & $414 / 295$ & $41 / 26$ & $140 / 66$ & $17 / 13$ & $196 / 89$ & $72 / 35$ \\
$A_{2.5-8}, \mathrm{~cm}^{-3}$ & $579 / 78$ & $123 / 19$ & $0 / 0$ & $12030 / 2290$ & $22 / 4$ & $671 / 66$ & $4 / 0.2$ & $1780 / 217$ & $1070 / 164$ \\
$A_{8-20}, \mathrm{~cm}^{-3}$ & $1460 / 371$ & $667 / 186$ & $23 / 6$ & $11040 / 7480$ & $283 / 73$ & $2190 / 389$ & $144 / 38$ & $3940 / 769$ & $1670 / 657$ \\
\hline
\end{tabular}

* Negative values are corrected to be equal to zero.

Table 3. The classification of nucleation events and the growth rates of newly formed particles during the BIOFOR III campaign (Kulmala et al., 2001a), positively charged fractions of aerosol particles, the correlation coefficients between the concentrations of positive air ions and aerosol particles in coinciding size ranges, and the maximum concentrations of aerosol particles during various nucleation event days. 2-29 April 1999, Hyytiälä.

\begin{tabular}{|c|c|c|c|c|c|c|c|c|}
\hline \multirow[b]{2}{*}{ Date } & \multirow[b]{2}{*}{ Class } & \multirow[b]{2}{*}{$\begin{array}{l}\text { Growth rate } \\
(\mathrm{nm} / \mathrm{h})\end{array}$} & \multicolumn{3}{|c|}{ Size class of particles $2.5-8 \mathrm{~nm}$} & \multicolumn{3}{|c|}{ Size class of particles $8-20 \mathrm{~nm}$} \\
\hline & & & $\begin{array}{l}\text { Charged } \\
\text { fraction } \\
(\%)\end{array}$ & $\begin{array}{l}\text { Correlation co- } \\
\text { efficient } \\
(\%)\end{array}$ & $\begin{array}{l}\text { Maximum of } \\
\text { aerosols } \\
\left(\mathrm{cm}^{-3}\right)\end{array}$ & $\begin{array}{l}\text { Charged frac- } \\
\text { tion } \\
(\%)\end{array}$ & $\begin{array}{l}\text { Correlation co- } \\
\text { efficient } \\
(\%)\end{array}$ & $\begin{array}{l}\text { Maximum } \\
\text { aerosols } \\
\left(\mathrm{cm}^{-3}\right)\end{array}$ \\
\hline 990402 & 1 & 6.7 & 4.9 & 83.6 & 2050 & 3.8 & 98.1 & 6810 \\
\hline 990403 & 2 & 2.2 & 3.0 & 43.5 & 840 & 4.2 & 95.4 & 3590 \\
\hline 990404 & 1 & 3.5 & 3.2 & 94.5 & 6470 & 3.9 & 94.5 & 9040 \\
\hline 990405 & 1 & 6.7 & 3.5 & 98.3 & 12030 & 3.5 & 94.1 & 11040 \\
\hline 990406 & 1 & 3.5 & 5.0 & 91.3 & 3290 & 4.0 & 87.7 & 5640 \\
\hline 990408 & 2 & 5.4 & 4.7 & 85.5 & 1790 & 4.3 & 95.7 & 4240 \\
\hline 990410 & 3 & 2.2 & 6.0 & 89.6 & 3500 & 3.9 & 90.2 & 3650 \\
\hline 990412 & 1 & 4.4 & 3.2 & 88.2 & 4390 & 3.7 & 95.6 & 4630 \\
\hline 990413 & 2 & 2.2 & 3.8 & 52.4 & 1400 & 3.4 & 92.3 & 5320 \\
\hline 990414 & 1 & 5.4 & 4.4 & 94.3 & 3480 & 4.2 & 95.8 & 4780 \\
\hline 990419 & 1 & 4.4 & 4.0 & 94.4 & 4450 & 5.1 & 89.8 & 2430 \\
\hline 990421 & 3 & 6.7 & $1.2^{*}$ & 4.4 & 270 & $2.0^{*}$ & 35.4 & 1710 \\
\hline 990427 & 2 & 4.4 & $0.4^{*}$ & 5.3 & 1080 & $0.4^{*}$ & 2.9 & 800 \\
\hline 990429 & 3 & 3.5 & 5.6 & 91.4 & 2770 & 4.4 & 97.5 & 5370 \\
\hline
\end{tabular}

* Estimates are of low significance.

The correlation between the concentrations of aerosol particles and intermediate air ions in Fig. 5a is substantially affected by the nucleation burst on 5 April, when the concentrations of nanometer particles $(2.5-8 \mathrm{~nm})$ up to $12030 \mathrm{~cm}^{-3}$ were recorded. Taking into account only the core of the scatterplot (data points below the particle concentration of about $5000 \mathrm{~cm}^{-3}$ ), the correlation coefficient decreases slightly from $87.6 \%$ down to $84.6 \%$, but the relationship (correlation curve) remains nearly the same. The coarse nanometer particles $(8-20 \mathrm{~nm}$ ) and their charged fraction (positive large air ions) in Fig. 5b are even more strongly correlated compared to nanometer particles; the correlation coefficient is $92 \%$. Detailed information about the correlation coefficients for various nucleation days is presented in Table 3. The particle formation events in Table 3 have been classified into three classes according to the amount of generated new nanometer particles and the clearness of the subsequent growth of par- ticles from the nucleation mode up to the Aitken mode size range (Kulmala et al., 2001a; Mäkelä et al., 2000). The best ones were classified as class 1 . The events with the high concentration of background aerosol or non-continuous growth characteristics were classified as classes 2 or 3 . We found that the correlation between the concentrations of nanometer particles and air ions was always linear during the nucleation bursts, considering different generation rates (followed by the maximum concentration of particles) and the growth rates of nanometer particles (Table 3). The event class 1 displayed the strongest correlation for the size class of $2.5-8 \mathrm{~nm}$, because the maximum concentrations of intermediate air ions are then well above the background (about $40 \mathrm{~cm}^{-3}$ ). Based on these results we can conclude that the air ion measurements can give essential information about the basic regularities of the behavior of nanometer aerosol particles. 
(a)

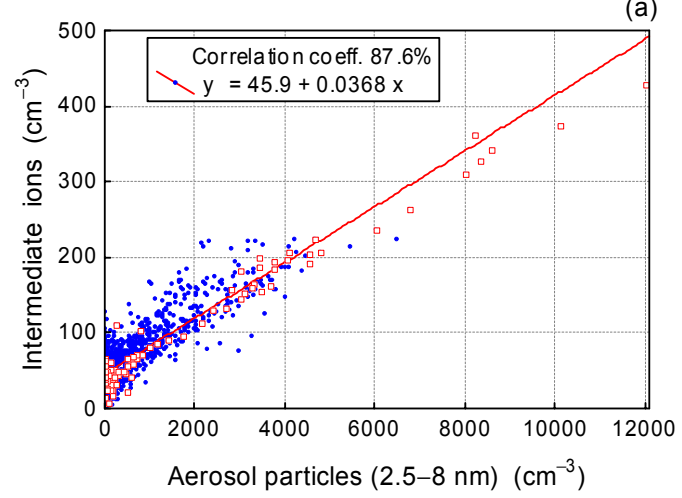

(b)

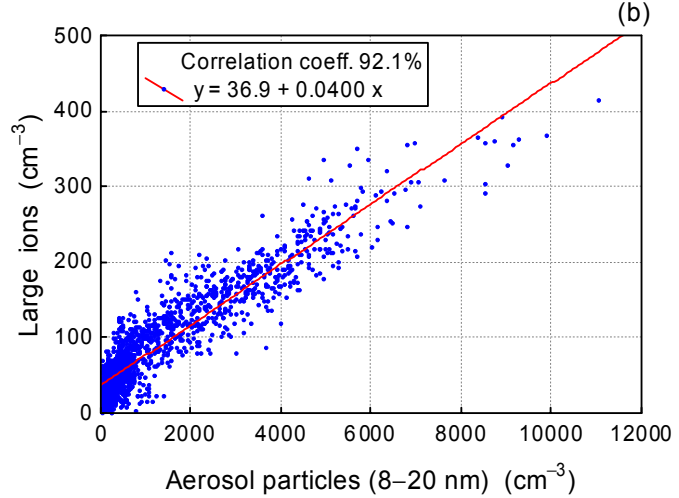

Fig. 5. Scatterplot between the concentrations of positive aerosol ions and aerosol particles: (a) intermediate ions ( $m$; $2.5-8 \mathrm{~nm})$ versus nanometer aerosol particles $(2.5-8 \mathrm{~nm})$. The data points corresponding to 5 April are marked with red squares ( $\square$ ). (b) Large air ions $(N$; 8-20 nm) versus aerosol particles (8-20 nm). Nucleation event days, 31 March-29 April 1999, Hyytiälä station.

Since the size fractions of particles measured by means of ion counters and the DMPS were related one-to-one, the scatterplot between the nanometer aerosol particles and their charged fraction (air ions) could be fitted with a line of the linear regression function, the intercept of which should be zero, and the slope giving the mean charging probability for the fraction. The results of the regression analysis showed a linear correlation between the nanometer aerosol particles and their charged fraction, but with a non-zero intercept of about $20-60 \mathrm{~cm}^{-3}$ (Fig. 5). This step at the zero value of the aerosol concentration (intercept) is probably due to methodological and instrumental uncertainties in the air ion fraction concentration estimation by means of integral ion counters (Tammet, 1970). This step in air ion concentration (average about $40-50 \mathrm{~cm}^{-3}$ ) was comparable, considering the size classes of $2.5-8 \mathrm{~nm}$ and $8-20 \mathrm{~nm}$ during nucleation events or the non-event days. In this study we did not take into account the non-zero intercept and interpreted the slope of the linear regression line as an estimate of the mean charged fraction of particles (or experimental charging probability). The estimates of the positively charged fraction of nanometer aerosol particles $(2.5-8 \mathrm{~nm})$ given in Table 3 varied in the range of $3-6 \%$. The average of the most pronounced events of class 1 is about $4 \%$. These estimates are close to the steady state bipolar charging probability of $2.6 \%$ for the mean size of the fraction of $5.3 \mathrm{~nm}$ (Reischl et al., 1996). Considering the measurement accuracy, we cannot state that the excess of positively charged nanometer particles indicates at an overcharge of atmospheric aerosols due to the ion-induced nucleation. The charged fractions of coarse nanometer aerosol particles $(8-20 \mathrm{~nm})$ given in Table 3 are only the order of magnitude estimates because of the uncertainty in the upper boundary of air ion size class. Despite that, it showed a nearly constant value, average about $4 \%$. The steady state bipolar charging probability for the mean size of the fraction of $12.7 \mathrm{~nm}$ should be about $7.2 \%$.
Recent measurements during the QUEST 2 campaign showed that the charge distribution on nanometer aerosol particles was often significantly asymmetric with an excess of negative charges below the particle diameter of about $5 \mathrm{~nm}$, decreasing as a function of particle size. The charging probability for the smallest nanometer particles (3-4 nm) varied during different nucleation event days in the range of about $2-6 \%$ and $2-15 \%$ for positively and negatively charged particles, respectively (Hõrrak et al., 2004a, b).

\subsection{Case studies}

Four nucleation event days were selected for the case studies to characterize the behavior of positive air ions of different classes: small ions, intermediate and large ions (Fig. 6). Some complementary information about the behavior of air ions and aerosol particles during these nucleation event days can be found in (Hõrrak et al., 2003a).

The diurnal variation in the concentration of small ions was different on different nucleation event days. On 2 April 1999, the data showed gradual increase in the concentration of small ions before the onset of the generation of nanometer aerosol particles at 12:30 LST. This is in general accordance with the decrease in the rate of ion sink on aerosol particles $(3-500 \mathrm{~nm})$ from $(5-6) \times 10^{-3} \mathrm{~s}^{-1}$ during the nighttime down to the minimum of $1.2 \times 10^{-3} \mathrm{~s}^{-1}$ in the afternoon (Fig. 7a). The ion sink rate stayed relatively constant (about $1.4 \times 10^{-3} \mathrm{~s}^{-1}$ ) during the intensive generation of nanometer particles. The increase in the ion sink rate caused by nanometer particles was compensated by the decrease in the concentration of the Aitken and accumulation mode particles. Therefore, no considerable changes in the concentration of small ions during the generation of nanometer aerosol particles can be found. The decrease followed the growth of new particles towards large sizes in the afternoon, when the particles in the size class of 8-20 nm displayed the concentration maximum. On 2 April, the concentrations of nanometer 
(a)

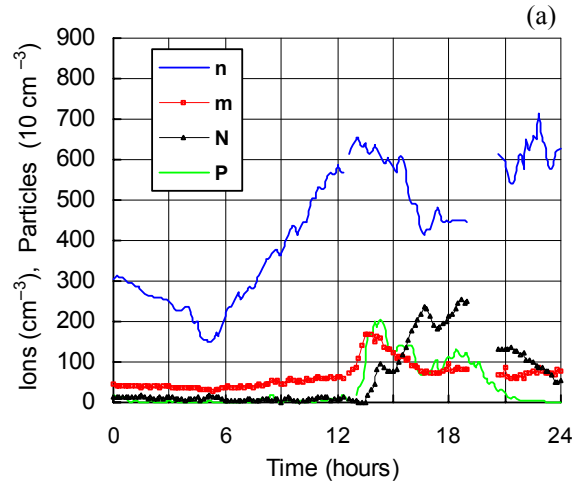

(c)

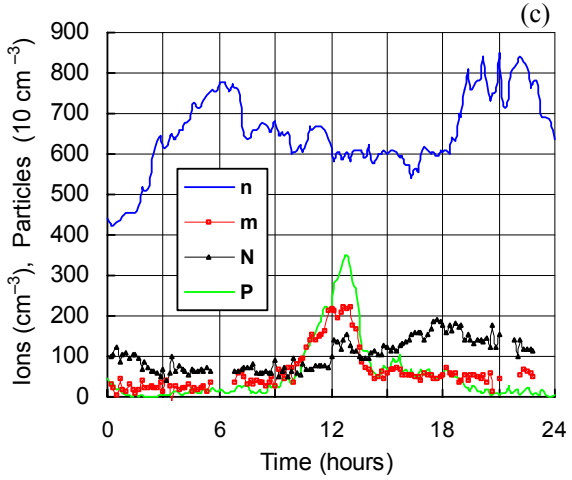

(b)

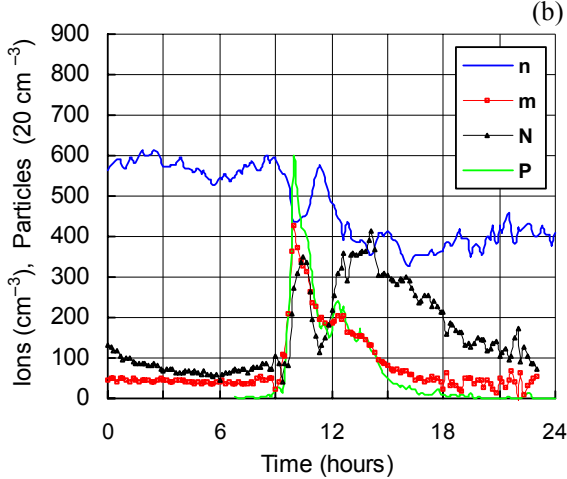

(d)

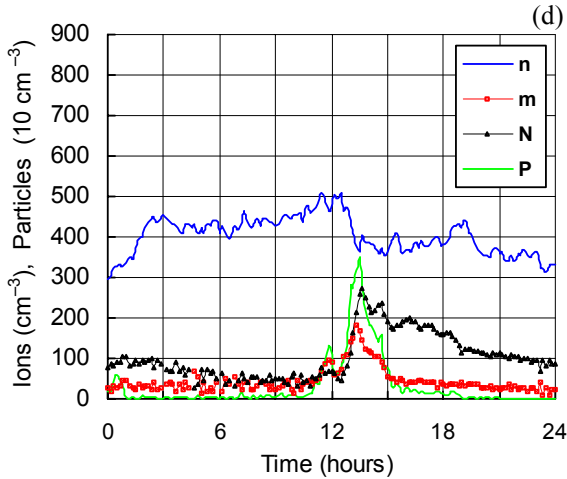

Fig. 6. Diurnal variation in the concentration of positive air ion classes: small ions ( $n$; diameters less than $2.5 \mathrm{~nm})$, intermediate ions $(m$; $2.5-8 \mathrm{~nm})$ and large ions $(N ; 8-20 \mathrm{~nm})$, as well as the total concentration of particles $(P ; 2.5-8 \mathrm{~nm})$ measured by the DMPS on 2 April (a), 5 April (b), 10 April (c) and 14 April 1999 (d) at Hyytiälä.

aerosol particles $(2.5-8 \mathrm{~nm})$ and their charged fraction (positive intermediate ions) showed only a modest correlation (the correlation coefficient was $84 \%$ ), because a rise in the concentration of intermediate ions precedes (about $10 \mathrm{~min}$, or one measurement cycle) that of aerosol particles measured by the DMPS, probably due to spatial inhomogeneity of the nucleation process.

A peculiarity of this day (2 April) was the fog, which was detected by means of optical spectrometers (ASASP-300, CSASP-100) during 02:00-07:00 LST in the morning with the maximum intensity around 04:50 a.m. The effect of the fog on the concentration of small ions is clearly visible in Fig. 7a, where the small ion concentration decreases independently of the ion sink rate (based on DMPS data) down to about $150 \mathrm{~cm}^{-3}$ around 04:50 a.m. The scatterplot between the small ion concentration and the ion sink rate in Fig. 9a revealed a separate group below the concentration of about $300 \mathrm{~cm}^{-3}$. Presumably the fog affects all the data below the small ion concentration of about $300 \mathrm{~cm}^{-3}$. Another separate group of data with a relatively high concentration of small ions up to $710 \mathrm{~cm}^{-3}$, which corresponds to the nighttime weak winds less than $0.2 \mathrm{~m} \mathrm{~s}^{-1}$, is probably due to the effect of radon on the ionization rate of the air. The nucleation event on 2 April, 1999, was analyzed in detail by Aalto et al. (2001).
The next example in Fig. 6c demonstrates the effect of clean air inflow on 10 April 1999. The increase in the concentration of small ions during the nighttime and early morning (up to $800 \mathrm{~cm}^{-3}$ ) followed the decrease in the ion sink rate from $5.5 \times 10^{-3} \mathrm{~s}^{-1}$ down to $3.9 \times 10^{-4} \mathrm{~s}^{-1}$ at 06:30 LST. The ion sink rate was decreasing due to the inflow of clean maritime air mass from the North Atlantic (Mäkelä et al., 2001b). The gradual increase in the ion sink rate after 06:30 LST up to $4.1 \times 10^{-3} \mathrm{~s}^{-1}$ at 24:00 LST was caused by the local production of aerosols (Fig. 7b). The rise in the concentration of small ions in the evening after 18:00 LST was probably due to the accumulation of radon favored during the nighttime calm and weak wind; the wind speed was below $0.5 \mathrm{~m} \mathrm{~s}^{-1}$ and the temperature inversion developed after 19:00 LST. This separate group with the high concentration of small ions is clearly seen in the scatterplot of the small ion concentration versus the ion sink rate in Fig. 9c.

A characteristic feature of 10 April was that the concentration of small ions in the clean air (very small ion sink on aerosols) was mainly determined by small ion recombination. Ion-ion recombination was responsible for $75 \%$ of the ion loss due to small ion recombination and attachment to the aerosol particles at 06:30LST. In the beginning of the burst of nanometer aerosol particles, the ion-ion recombination was responsible for $40-55 \%$ of the ion loss (estimated by 

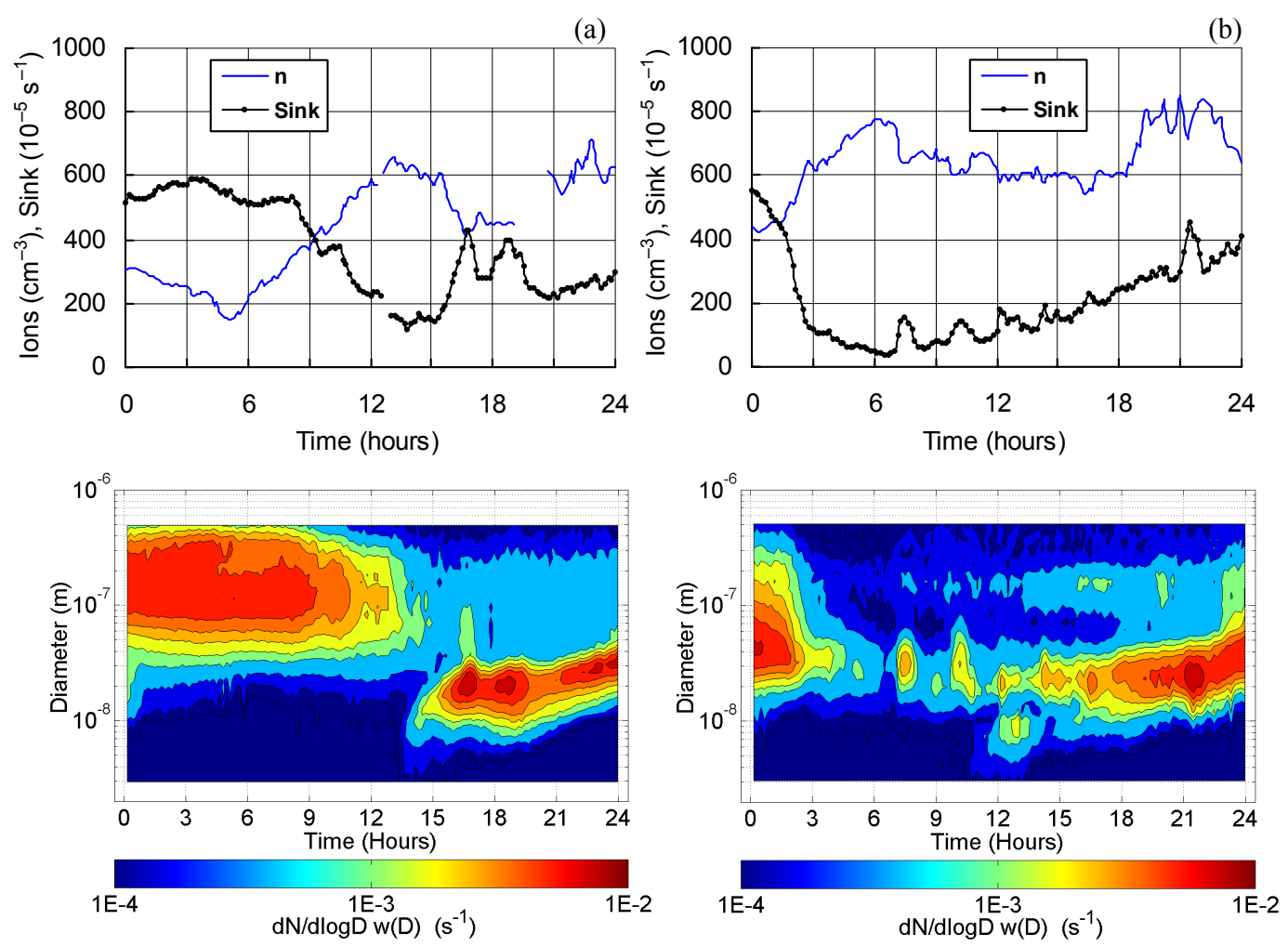

Fig. 7. Diurnal variation in the concentration of positive small ions $(n)$, ion sink $\left(S_{a}\right)$ and the size distribution of the ion sink by aerosol particle sizes (3-500 nm) on 2 April (a; left) and 10 April 1999 (b; right) at Hyytiälä.

means of Eq. (1) considering the steady state condition and neglecting the effect of ion-induced nucleation). During the other days selected for the case studies (on 2, 5 and 14 April) the maximum percentage of ion loss caused by small ion recombination was $44 \%, 30 \%$ and $20 \%$, respectively. Just before the burst of nanometer particles, these percentages were $27 \%, 25 \%$ and $20 \%$, respectively. The hypothetical ion loss due to the enhanced deposition of small ions on the coniferous forest discussed in Sect. 4.3 was not taken into account in these estimates. Taking into account also the extra ion loss, the maximum percentage of small ion losses due to ion-ion recombination decreased about 4 times down to $17 \%$ on 10 April. On the other days, on 2, 5 and 14 April this percentage was $13 \%, 11 \%$ and $9 \%$, respectively.

5 and 14 April 1999, were the only days during the BIOFOR III campaign when the concentration of small ions was considerably decreasing during the nucleation burst (Fig. 6b, d). These days are of particular interest to the study of the hypothetical role of ion-induced nucleation on the decrease of small ion concentration. The nucleation burst on 5 April was the most intensive in April, with the peak concentration of nanometer particles $(2.5-8 \mathrm{~nm})$ of about $12000 \mathrm{~cm}^{-3}$, which is about two times higher than on other days. On 5 April, the minimum of the ion sink rate (about $2 \times 10^{-3} \mathrm{~s}^{-1}$ ) was recorded before the burst of nanometer particles at 09:00 LST (Fig. 8a). The decrease in the concentration of small ions occurred simultaneously with a rapid increase in the concentration of intermediate ions $(2.5-8 \mathrm{~nm})$, as well as the concentration of nanometer aerosol particles recorded by the DMPS. The oscillation in the concentration of small ions after the nucleation burst was correlated with the changes in the rate of ion sink on coarse nanometer particles (8-20 nm) (Figs. 6b and 8a).

Also on 14 April, the ion sink rate displayed the minimum $\left(2.9 \times 10^{-3} \mathrm{~s}^{-1}\right)$ before the onset of the generation of nanometer particles at noon (12:20 LST) (Fig. 8b); the decrease of small ions followed after that. Similarly to the previous case (on 5 April), the concentrations of fine nanometer particles $(2.5-8 \mathrm{~nm})$ and coarse nanometer particles $(8-$ $20 \mathrm{~nm}$ ) started to increase almost simultaneously, afterwards displaying a delay in the peak concentrations about $30 \mathrm{~min}$ (Fig. 6b and d). In general, the delay between the concentration maxima of two ion or particle classes, affected by the particle growth towards large sizes after the generation, was many times longer (about $3.5 \mathrm{~h}$ ). The growth rate of nanometer particles (in the size range of 3-10 nm) on 5 and 14 April was comparatively high: 6.7 and $5.4 \mathrm{~nm} \mathrm{~h}^{-1}$, respectively (Table 3). The study of the evolution of the distribution of the ion sink rate by particle sizes on 5 and 14 April (Fig. 8) confirms that the decrease in the concentration of small ions was 
(a)
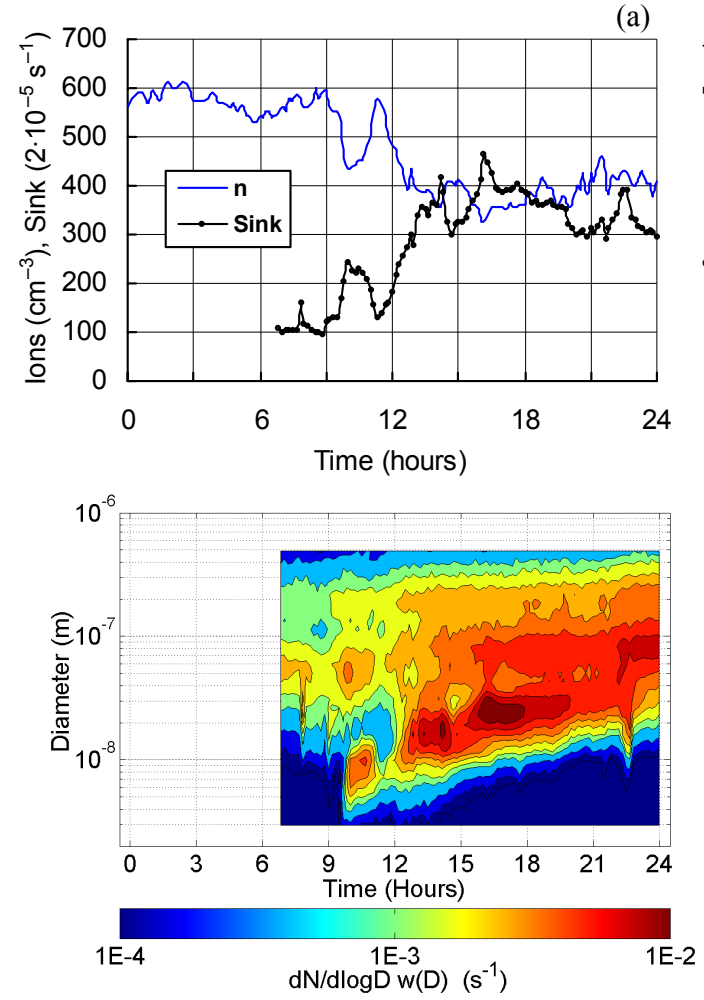

(b)
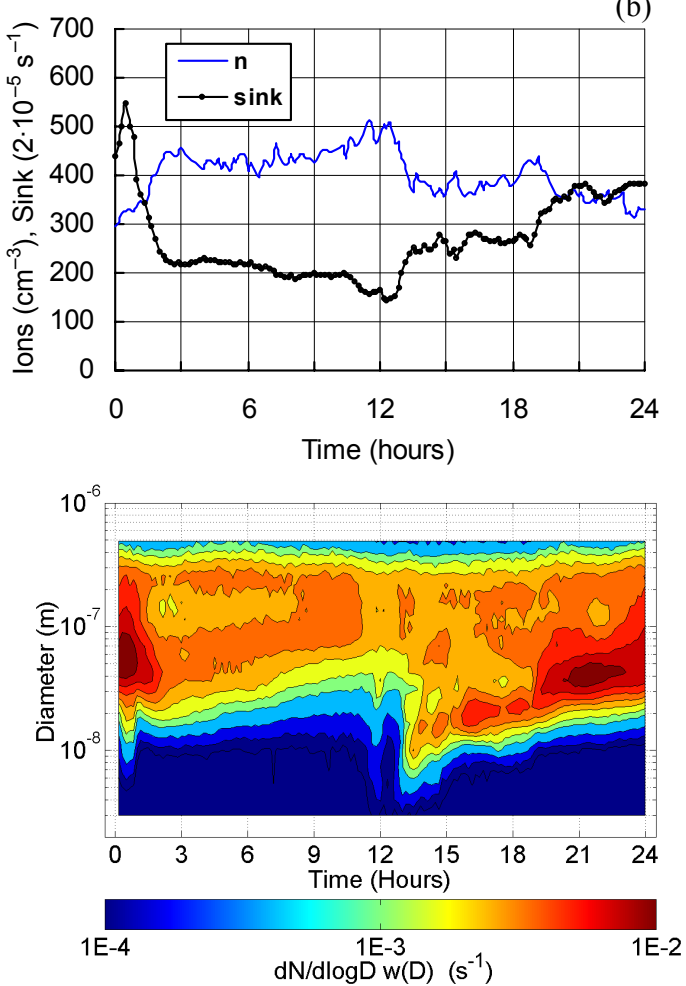

Fig. 8. Diurnal variation in the concentration of positive small ions $(n)$, ion sink $\left(S_{a}\right)$ and the size distribution of the ion sink by aerosol particle sizs (3-500 nm) on 5 April (a; left) and 14 April 1999 (b; right) at Hyytiälä.

caused by an intensive generation of nanometer aerosol particles followed by a rapid growth of particles towards large sizes. The scavenging efficiency of small ions by aerosol particles in the size class of $8-20 \mathrm{~nm}$ is about 3 times higher compared to the particles in the size class of $2.5-8 \mathrm{~nm}$. Thus, on both days the decrease in the small ion concentrations can well be explained by the effect of aerosols (Fig. 9b, d).

The nucleation events on both 5 and 14 April, with a rapid increase in the concentration of intermediate ions $(2.5-8 \mathrm{~nm})$ and large ions $(8-20 \mathrm{~nm})$, showed a good correlation between the nanometer aerosol particles and their charged fraction (positive air ions) (Table 3). Kulmala et al. (2001b) applied an analytical model and found that the formation rate of $3 \mathrm{~nm}$ particles was $1.6 \mathrm{~cm}^{-3} \mathrm{~s}^{-1}$ on 5 April and $1.1 \mathrm{~cm}^{-3} \mathrm{~s}^{-1}$ on 14 April. The estimated nucleation rates (generation rate of $1 \mathrm{~nm}$ particles) were $10-100 \mathrm{~cm}^{-3} \mathrm{~s}^{-1}$ and $50-80 \mathrm{~cm}^{-3} \mathrm{~s}^{-1}$, respectively.

As a result of the case studies, we can conclude that both the ion sink on aerosols and small ion recombination are essential factors of small ion loss in the comparatively clean air at Hyytiälä. If the nucleation burst of nanometer particles is able to cause changes in the ion sink rate by about $2 \times 10^{-3} \mathrm{~s}^{-1}$, then the effect is clearly observable in the concentration of small ions. This change in the ion sink rate is significant considering the extent of its variation during nucleation event days (Fig. 9).
Examination of the nucleation events selected for the case studies, as well as other events during the BIOFOR III campaign at Hyytiälä, did not show any clear indication of the ion-induced nucleation in the atmosphere - the scavenging of small ions before or during intensive generation of nanometer particles. In general, it is accepted that the nucleation on small ions is energetically more favored compared to particle formation by homogeneous nucleation from pure vapor(s) (Hoppel et al., 1994; Raes and Van Dingenen, 1992; Nadykto and Yu, 2003). In some cases, the barrierless nucleation can occur, e.g. nucleation of $\mathrm{H}_{2} \mathrm{SO}_{4}$ on negative small ions (Lovejoy et. al., 2004). On the other hand, the analysis of the nucleation events by Kulmala et al. (2001b) revealed that the nucleation rate (or the formation rate of $1 \mathrm{~nm}$ particles) should be in the range of $10-100 \mathrm{~cm}^{-3} \mathrm{~s}^{-1}$ to explain the formation rate of $3 \mathrm{~nm}$ particles of about $1 \mathrm{~cm}^{-3} \mathrm{~s}^{-1}$ during the BIOFOR III campaign at Hyytiälä. Such high nucleation rates (compared to the ionization rate of about 4-6 ion pairs $\mathrm{cm}^{-3} \mathrm{~s}^{-1}$ ) should reduce the concentration of small ions assuming that the small ions are involved in the nucleation process. However, the measurements did not exhibit significant decrease in the concentration of positive small ions as the indication of ion-induced nucleation during nucleation bursts. If the concentration decreased, then it correlated well with the rate of ion sink on aerosol particles. The recent QUEST 2 campaign measurements at Hyytiälä in spring 

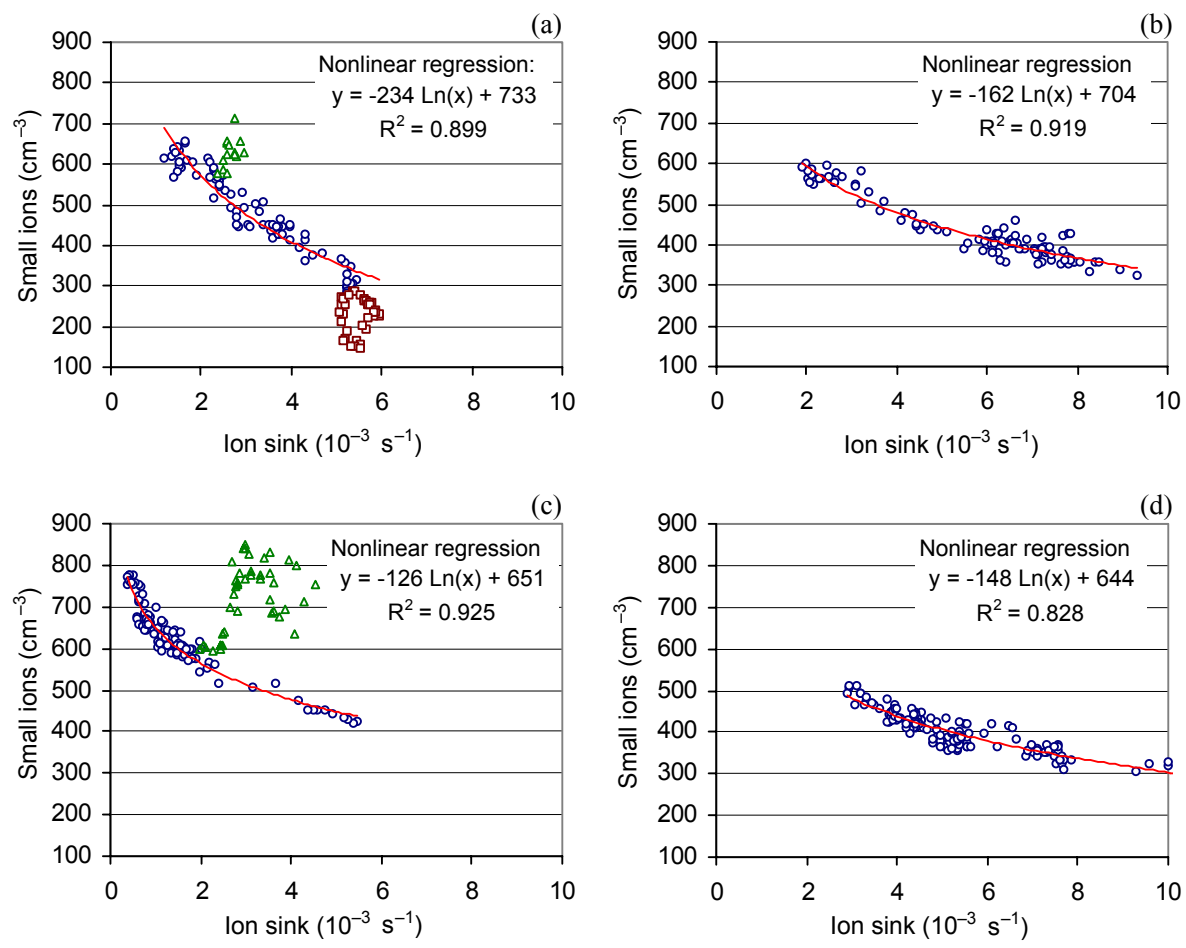

Fig. 9. Scatterplot between the positive small ion concentration and ion sink rate on 2 April (a), 5 April (b), 10 April (c) and 14 April 1999 (d) at Hyytiälä station. Specific data points: brown squares $(\square)$ correspond to the fog event; green triangles $(\Delta)$ correspond to the period of weak wind less than $0.2 \mathrm{~m} \mathrm{~s}^{-1}$. Specific data points have been excluded from the regression analysis.

2003 indicated that also the concentration of negative small ions behaved similarly during the nucleation bursts; even the excess of negative intermediate ions $(1.6-5 \mathrm{~nm})$ and the negative overcharge on nanometer aerosol particles $(3-5 \mathrm{~nm})$ was found (Hõrrak et al., 2004a, b; Laakso et al., 2004b). The latter is indeed a clear indication of ion-induced nucleation on negative small ions. As a result, we can conclude that at Hyytiälä, the positive small ions less likely nucleate (probably due to thermodynamic properties proposed by Froyd and Lovejoy, 2003a, b) and the ion-induced nucleation rate is always less than the ionization rate. Therefore, the small ion concentration does not reflect the changes caused by ioninduced nucleation, probably because its variability due to other factors (e.g. ionization rate, ion sink on aerosols, turbulent mixing of air) is commonly considerably higher.

4.6 Study of the effect of the hygroscopic growth of aerosol particles on the ion sink rate and on the ionization rate

The dependence of the hygroscopic growth factor (GF) of submicron particles $(\mathrm{d}<0.53 \mu \mathrm{m})$ on ambient relative humidity $(\mathrm{RH})$ was estimated according to the parameterization given by Laakso et al. (2004b)

$\mathrm{GF}=\frac{d_{\mathrm{wet}}}{d_{\mathrm{dry}}}=\left(1-\frac{\mathrm{RH}}{100}\right)^{-\frac{d_{\mathrm{dry}}}{3215 \mathrm{~nm}}-0.0847}$
Equation (9) is based on a simple model by Zhou et al. (2001), wherein the exponent as a function of particle size was found from the particle GF measurements in the size range of 10-264 nm, carried out at Hyytiälä during the BIOFOR III campaign (Hämeri et al., 2001). The model gives an estimate of the average GF for externally mixed aerosols of different hygroscopic growth modes weighted by their corresponding fractions. In general, Eq. (9) is valid in the case of ambient relative humidity $\mathrm{RH} \leq 90 \%$ and the particle sizes below $270 \mathrm{~nm}$. Above these limits, the model has not been verified due to the absence of corresponding particle GF measurements at Hyytiälä. In accordance with the recent results of the particle wet and dry size distribution measurements at Hyytiälä during May and July 2004 (Birmili et al., 2006), we have limited the GF of particles larger than $280 \mathrm{~nm}$ with that found for $280 \mathrm{~nm}$ size particles. The latter is argued, since by Birmili et al. (2006) the particles of 200-400 nm showed nearly the same hygroscopic properties. Thus, with certain reservations, the GF model (Eq. 9) can be applied for the particles up to about $500 \mathrm{~nm}$ and for ambient RHs up to about $95 \%$. In the case of high RH of $96-99 \%$, where the uncertainty of the RH measurements is about $3 \%$ and the particle GF can change by a factor of 1.5-2 (Wex et al., 2005; Svenningsson et al., 2006), the exploitation of the model is the most critical. 
Table 4. The statistics of positive small ion balance in the atmosphere corrected by ambient relative humidity: effective attachment coefficient ( $\beta_{\text {eff }}$ ), the sink of small ions on aerosol particles of 3-500 $\mathrm{nm}\left(S_{a}\right)$, the ionization rate $(q)$, the ratio of ion loss due to the recombination to total ion loss due to particles $\left(\alpha \cdot n /\left(\alpha \cdot n+S_{a}\right)\right.$, and corrected by the extra ion loss due to the forest $\left(S_{e}=6.3 \times 10^{-3} \mathrm{~s}^{-1}\right)$ the values of the ionization rate $\left(q_{e}\right)$ and the ratio of $\alpha \cdot n /\left(\alpha \cdot n+S_{a}+S_{e}\right)$. The air temperature $(T)$ and relative humidity $(\mathrm{RH})$ are presented in the last rows of the tables as well. 31 March-29 April 1999, Hyytiälä.

a) Nucleation event days (number of measurements 1813).

\begin{tabular}{llllllllll}
\hline & Mean & Median & Min & Max & $\begin{array}{l}\text { Lower } \\
\text { Quartile }\end{array}$ & $\begin{array}{l}\text { Upper } \\
\text { Quartile }\end{array}$ & $\begin{array}{l}\text { Percentile } \\
10\end{array}$ & $\begin{array}{l}\text { Percentile } \\
90\end{array}$ & Std.Dev. \\
\hline$\beta_{\text {eff }}, 10^{-6} \mathrm{~cm}^{3} \mathrm{~s}^{-1}$ & 1.5 & 1.3 & 0.20 & 4.4 & 0.68 & 2.2 & 0.44 & 3.1 & 1.0 \\
$S_{a}, 10^{-3} \mathrm{~s}^{-1}$ & 4.9 & 4.6 & 0.45 & 13 & 3.0 & 6.4 & 1.8 & 8.5 & 2.5 \\
$q, \mathrm{~cm}^{-3} \mathrm{~s}^{-1}$ & 2.8 & 2.6 & 1.0 & 8.7 & 2.1 & 3.3 & 1.6 & 4.2 & 1.1 \\
$\alpha \cdot n /\left(\alpha \cdot n+S_{a}\right)$ & 0.18 & 0.14 & 0.018 & 0.72 & 0.096 & 0.24 & 0.063 & 0.33 & 0.12 \\
$q e, \mathrm{~cm}^{-3} \mathrm{~s}^{-1}$ & 6.2 & 5.6 & 1.7 & 13 & 5.2 & 6.8 & 4.8 & 8.5 & 1.5 \\
$\alpha \cdot n /\left(\alpha \cdot n+S_{a}+S_{e}\right)$ & 0.071 & 0.066 & 0.011 & 0.16 & 0.051 & 0.090 & 0.037 & 0.11 & 0.071 \\
$\mathrm{RH}, \%$ & 60.7 & 58.7 & 25.4 & 98.3 & 44.7 & 75.6 & 36.4 & 89.5 & 19.0 \\
$T,{ }^{\circ} \mathrm{C}$ & 3.4 & 3.5 & -6.2 & 15.6 & 0.8 & 5.9 & -2.1 & 8.2 & 4.2 \\
\hline
\end{tabular}

b) Non-event days (number of measurements 1754).

\begin{tabular}{llllllllll}
\hline & Mean & Median & Min & Max & $\begin{array}{l}\text { Lower } \\
\text { Quartile }\end{array}$ & $\begin{array}{l}\text { Upper } \\
\text { Quartile }\end{array}$ & $\begin{array}{l}\text { Percentile } \\
10\end{array}$ & $\begin{array}{l}\text { Percentile } \\
90\end{array}$ & Std.Dev. \\
\hline$\beta_{\mathrm{eff}}, 10^{-6} \mathrm{~cm}^{3} \mathrm{~s}^{-1}$ & 3.0 & 3.0 & 0.75 & 6.2 & 2.1 & 3.7 & 1.4 & 4.7 & 1.2 \\
$S_{a}, 10^{-3} \mathrm{~s}^{-1}$ & 9.7 & 6.9 & 1.7 & $66^{*}$ & 5.4 & 11 & 4.3 & 19 & 7.5 \\
$q, \mathrm{~cm}^{-3} \mathrm{~s}^{-1}$ & 3.7 & 3.4 & 1.0 & $16^{*}$ & 2.6 & 4.4 & 2.1 & 5.5 & 1.7 \\
$\alpha \cdot n /\left(\alpha \cdot n+S_{a}\right)$ & 0.090 & 0.081 & 0.005 & 0.39 & 0.036 & 0.13 & 0.018 & 0.18 & 0.065 \\
$q_{e}, \mathrm{~cm}^{-3} \mathrm{~s}^{-1}$ & 6.4 & 6.1 & 1.8 & $18^{*}$ & 4.9 & 7.3 & 4.2 & 8.8 & 2.2 \\
$\alpha \cdot n /\left(\alpha \cdot n+S_{a}+S_{e}\right)$ & 0.046 & 0.044 & 0.004 & 0.15 & 0.024 & 0.061 & 0.014 & 0.083 & 0.027 \\
$\mathrm{RH}, \%$ & 77.5 & 79.5 & 35.9 & 100 & 63.8 & 94.8 & 50.9 & 98.0 & 18.0 \\
$T,{ }^{\circ} \mathrm{C}$ & 5.9 & 4.7 & -1.7 & 18.8 & 2.8 & 8.2 & 1.4 & 12.1 & 4.3 \\
\hline
\end{tabular}

* Elimination of the probable local pollution episodes (two events with 47 measurements), reduces the maximum of the ion sink $\left(S_{a}\right)$ down to $3.5 \times 10^{-2} \mathrm{~s}^{-1}$ in Table $4 \mathrm{~b}$ and the corresponding maximum values of the ionization rates $\left(q\right.$ and $\left.q_{e}\right)$ down to about 10 ion pairs $\mathrm{cm}^{-3} \mathrm{~s}^{-1}$ and 16 ion pairs $\mathrm{cm}^{-3} \mathrm{~s}^{-1}$, respectively.

Statistical description of the parameters given in the Table 1 , corrected by the ambient relative humidity, is presented in Table 4, together with the air temperature and relative humidity. Here we have limited the ambient relative humidity by $99 \%$ in calculations. In general, the changes in the mean and median values of recalculated parameters due to the effect of hygroscopic growth of aerosol particles $(3-500 \mathrm{~nm})$ are in the range of $10 \%-33 \%$. The changes are about 1.5 2.3 times smaller in the case of nucleation event days if compared to non-event days owing to different meteorological conditions. Thus, the aerosol data correction by the hygroscopic growth factor accounts for about $18 \%$ and $28 \%$ increase in the mean rate of ion sink on aerosol particles in the case of nucleation event days and non-event days, respectively. Correspondingly, the mean ionization rate also increases by about $13 \%$ and $23 \%$ (see Tables 1 and 4). The average diurnal variations in the ion sink rate, effective attachment coefficient and ionization rate discussed in Sect. 4.1 showed about $25 \%, 33 \%$ and $12 \%$ increase in amplitude, respectively, due to higher nighttime maxima of the parameters induced by the hygroscopic GF correction of aerosol data.
The limitation of the GF for particles larger than $280 \mathrm{~nm}$ results in a small decrease less than $4 \%$ in the ion sink rate, since the ion sink at Hyytiälä was mainly caused by the accumulation mode particles. The dependence of the ion sink, found from the DMPS measurements applying the hygroscopic growth correction (Eq. 9), on ambient relative humidity can well be approximated by the same power function (Eq. 9) with the particle dry diameter of $154 \mathrm{~nm}$ in the exponent. The nonlinear correlation coefficient between the relative humidity and the ratio of ion sink rate corrected by the ambient humidity to that based on original data is $98.8 \%$. The ratio increases moderately from the value of 1.07 at $\mathrm{RH}=40 \%$ up to 1.24 at $\mathrm{RH}=80 \%$ and henceforth, rises exponentially from 1.36 at $\mathrm{RH}=90 \%$ up to 1.84 at $\mathrm{RH}=99 \%$. Nearly similar humidity dependence of the ratio of the calculated ionization rates (ratio of corrected by RH to the original) was found with the ratios of 1.06, 1.19, 1.31 and 1.84 corresponding to the relative humidities of $40 \%, 80 \%, 90 \%$ and $99 \%$, respectively. The correlation coefficient between the ratio and RH was $97.9 \%$. This demonstrates the importance of the GF correction of the DMPS measurements, when 
estimating the ion sink rate (especially in the case of high relative humidity) and the necessity for appropriate GF models.

In general, the contribution of wet coarse particles $(0.52-$ $32 \mu \mathrm{m}$ ) measured by the optical particle counters (ASASP300 and CSASP-100) to the total rate of ion sink on aerosols (taking into account also the hygroscopic growth correction of the DMPS data) was less than $8 \%$ (the mean was about $0.7 \%$ ) if the $\mathrm{RH}<96 \%$, but it increased exponentially up to an order of magnitude (up to $84 \%$ ) above the $\mathrm{RH}=96 \%$. The corresponding numbers for the percentage of the total ion loss (due to particles and the extra ion loss in the forest canopy) are, in average, about 2 times smaller if the $\mathrm{RH}<96 \%$; the maximum in the case of $\mathrm{RH}>96 \%$ was $76 \%$. Thus, the coarse particles (above $0.52 \mu \mathrm{m}$ ) can be ignored in calculations of the ion sink rate at the Hyytiälä SMEAR II station only if to exclude the situations of high relative humidity, which are often accompanied with fog formation. Such situations were eliminated from the database to determine the ionization rate (given below), and set aside for future analysis due to the lack of complete information about the size distribution of fog droplets above $32 \mu \mathrm{m}$ necessary for the ion sink calculation.

Considering the statistical estimate of the extra ion loss of $5.2 \times 10^{-3} \mathrm{~s}^{-1}$ due to small ion deposition inside the forest canopy, in addition to the ion sink on aerosol particles found in Sect. 4.3, results in the ionization rate of about 4.8 ion pairs $\mathrm{cm}^{-3} \mathrm{~s}^{-1}$. The recalculated values of the parameters using the same method as described in Sect. 4.3 and taking into account also the effect of hygroscopic growth of particles on the ion sink below the $\mathrm{RH}=96 \%$ are about $15 \%$ and $20 \%$ higher -5.5 ion pairs $\mathrm{cm}^{-3} \mathrm{~s}^{-1}$ and $6.3 \times 10^{-3} \mathrm{~s}^{-1}$ respectively. The estimates of the standard error (standard deviation of the sample mean) of the parameters are 0.11 ion pairs $\mathrm{cm}^{-3} \mathrm{~s}^{-1}$ and $2.1 \times 10^{-4} \mathrm{~s}^{-1}$, respectively. The statistics of the ionization rate $\left(q_{e}\right)$, calculated from the balance equation corrected by the extra ion loss $\left(S_{e}\right)$ of $6.3 \times 10^{-3} \mathrm{~s}^{-1}$, are given in Table 4. The mean values of the ionization rate $\left(q_{e}\right)$ in Table 4 are somewhat higher, compared to the value of 5.5 ion pairs $\mathrm{cm}^{-3} \mathrm{~s}^{-1}$, given above due to the contribution of the data with relative humidity above $95 \%$ and wind speed less than $1 \mathrm{~m} \mathrm{~s}^{-1}$. The extra ion loss further decreases the percentage of small ion loss due to ion-ion recombination down to $6.2 \%$, in average, and the maximum down to $16 \%$ (see Table 4 ).

Correction of the size distributions of particles measured with the DMPS by hygroscopic growth factor, as well as taking into account the particle measurements above $500 \mathrm{~nm}$ at ambient humidity by the optical particle counters, changes the overall poor correlation between the small ion concentration and the ion sink rate depicted in Fig. 3a. The nonlinear correlation coefficient $(R)$ increases from 0.59 (the determination coefficient $\left.R^{2}=0.35\right)$ up to $0.74(0.55)$. The both above-mentioned factors have nearly the same contribution ( 0.09 and 0.06 , respectively) to the increase in the correlation coefficient by decreasing the dispersion of data-points in the case of high humidity. In Fig. 3a, the effect is the most essential in the central region of the correlation field below the regression curve, where the highly deviated datapoints are moved towards higher ion sink rates up to about $6 \times 10^{-2} \mathrm{~s}^{-1}$. The increase in the median rate of ion sink is about $33 \%$. In the case of Fig. $3 \mathrm{~b}$ and Fig. 4, the contribution of large aerosol particles above $500 \mathrm{~nm}$ to the ion sink is insignificant and the hygroscopic growth correction of the DMPS data increases the ion sink rate by a factor of 1.18 and 1.14 , respectively. The increase in the correlation coefficient is still less than $2 \%$.

Regarding the examples selected for case studies in Fig. 9, the general regularities between the small ion concentration and ion sink rate stayed nearly the same in all four days, if to compare the ion sinks from dry and wet particle size distributions. On 5, 10 and 14 April, the maxima of ion sink rates by the DMPS data considering the hygroscopic growth correction of particle sizes were about $7 \%, 20 \%$ and $15 \%$ higher, respectively, but the changes in the correlation (determination) coefficients were insignificant. The ratios of wet to dry sink rate of ions were changing in the range of 1.06-1.27, 1.05-1.2 and 1.1-1.2 during 5, 10 and 14 April, respectively, depending on the diurnal variation in relative humidity. The minima were found to take place at local noon. On 2 April, during the nucleation burst in the afternoon, the changes in the ratio of wet to dry sink rate of ions were similar to that found for 10 April. However, the ratio was changing drastically in the early morning during the fog $(03: 30-$ 06:30), when the maximum ratio of about 9 was recorded at 5 o'clock. Then the ion sink from the wet large particles $(0.52-$ $32 \mu \mathrm{m}$ ) was about $80 \%$ of the total ion sink on aerosols, and the hygroscopic growth correction of the DMPS measurements $(3-500 \mathrm{~nm})$ increased the corresponding ion sink rate by a factor of 1.7. During the other days, the contribution of large particles was less than $6 \%$, commonly $0.5-2 \%$. Thus, taking into account the above-mentioned corrections in the ion sink, the data-points corresponding to the high relative humidity and fog event in Fig. 9a (brown squares) are spread towards considerably higher ion sink rates up to $4.9 \times 10^{-2} \mathrm{~s}^{-1}$. Therefore, considering all the data on 2 April, the determination coefficient between the concentration of small ions and ion sink rate increases from $87.1 \%$ to $89.5 \%$.

\section{Conclusions}

On the basis of the measurements carried out during the BIOFOR III campaign, we can point out the following characteristics of the behaviour of positive air ions at boreal forest in early spring.

The concentration of small (or cluster) ions at the Hyytiälä station varied from 110 to $1183 \mathrm{~cm}^{-3}$, the average was about $480 \mathrm{~cm}^{-3}$. The highest concentrations were recoded during the nighttime calms and after the inflow of clean maritime air masses. The smallest concentrations below about $300 \mathrm{~cm}^{-3}$ 
belonged to fog events and polluted continental air masses with a high aerosol load. No clear indication of ion-induced nucleation (scavenging of small ions) was found considering the behavior of positive small ions during nucleation events.

The variation in the concentration of small ions can well be explained by the changes in ion loss due to aerosols (ion sink). Exceptions are the nighttime calms and weak wind, when the increase in the concentration of small ions (up to about $1000 \mathrm{~cm}^{-3}$ ) is probably due to the effect of radon on the ionization rate of air. The concentration of small ions decreases independently of fine aerosol particles $(3-500 \mathrm{~nm})$ measured by the DMPS at high humidity (above 96\%), presumably due to the increasing ion sink rate caused by hygroscopic growth of particles and scavenging by fog droplets. The nonlinear correlation between the small ion concentration and the ion sink rate for the selected hours (wind speed $>0.6 \mathrm{~m} \mathrm{~s}^{-1}$, relative humidity $<95 \%$ ) was $-87 \%$. Study of the effect of the hygroscopic growth of aerosol particles on the ion sink and ionization rate demonstrates the importance of the hygroscopic growth correction of the aerosol particle size distributions measured by the DMPS, as well as the importance of the contribution of wet coarse particles above $500 \mathrm{~nm}$ in the case of high relative humidity (>96\%) and fog events.

In addition to small ion loss due to recombination and attachment to aerosol particles, the term of an "extra ion loss", presumably due to small ion deposition on coniferous forest, is needed to explain the observations. This extra ion loss, which rate is nearly equal to the mean rate of ion sink on aerosol particles, is significant and should be taken into account, when estimating the balance of small ions inside the forest. The loss of small ions by small ion recombination cannot be ignored; its contribution to the total ion loss was about $6 \%$ in average; the maximum of $16 \%$ was recorded in the case of Arctic clean air advection from the North Atlantic.

The ion sink rate on aerosols varied in the range of $4.5 \times 10^{-4}-6.6 \times 10^{-2} \mathrm{~s}^{-1} \quad$ (commonly $1 \times 10^{-3}$ $\left.1.2 \times 10^{-2} \mathrm{~s}^{-1}\right)$ at the Hyytiälä station. It was mainly determined by the concentration of particles in the size range of 3-500 nm; the contribution of larger particles of the sizes of $0.52-32 \mu \mathrm{m}$ was about $1-2 \%$ in average and always less than $8 \%$ if the relative air humidity was less than $96 \%$. However, sometimes the contribution of coarse particles can be as high as $70 \%-80 \%$ in the case of high relative humidity and fog. In general, the main contribution was made by the particles in the Aitken and accumulation mode size ranges. The nucleation mode particles $(3-20 \mathrm{~nm})$ had an effect on the concentration of small ions only sometimes during an intensive generation of nanometer particles followed by a rapid growth of particles towards large sizes.

In the nucleation event days, the minimum in the ion sink rate occurred before the onset of the generation of nanometer particles or at about the burst peak. Before the onset, the fine aerosols $(3-500 \mathrm{~nm})$ were responsible for $37-88 \%$ (commonly $65-83 \%$ ) of the total ion loss due to small ion recombination and attachment to the aerosol particles. The mean rate of ion sink on aerosols was about 1.8 times smaller during the nucleation event days compared to the non-event days, and the mean concentration of small ions was correspondingly higher: $530 \mathrm{~cm}^{-3}$ versus $424 \mathrm{~cm}^{-3}$.

The ion sink is affected by the total concentration of particles and by the changes in the effective attachment coefficient of small ions onto aerosol particles. The effective attachment coefficient (which is nearly proportional to the mean diameter of aerosol particles) varied in the range of $2 \times 10^{-7}-6.2 \times 10^{-6} \mathrm{~cm}^{3} \mathrm{~s}^{-1}$. It showed a considerable diurnal variation during the nucleation burst days due to transformations in the aerosol particle size distribution initiated by the mixing of boundary layer and new particle formation. During the peak time of nanometer particle generation around noon, the effective attachment coefficient was almost always less than $6 \times 10^{-7} \mathrm{~cm}^{3} \mathrm{~s}^{-1}$.

The average ionization rate of about 3.3 ion pairs $\mathrm{cm}^{-3} \mathrm{~s}^{-1}$, calculated from the small ion balance equation applying experimental data of aerosol particle size distribution (with hygroscopic growth correction of particle sizes) and small ion concentration measurements, is too small for continental stations. The relationship between the concentration of small ions and the rate of ion sink on aerosol particles is far from the dependence predicted by the balance equation of small ions. The best fit to experimental data was found assuming an extra ion loss of $6.3 \times 10^{-3} \mathrm{~s}^{-1}$ (presumably due to small ion deposition on the coniferous forest) in addition to the ion sink on aerosol particles. Therefore, the estimated average total ionization rate at the Hyytiälä station at a height of about $2 \mathrm{~m}$ above the ground during early spring, when the ground was wet and partly covered with snow, was found to be about 6.2 ion pairs $\mathrm{cm}^{-3} \mathrm{~s}^{-1}$ with the standard deviation of sample of 1.9 ion pairs $\mathrm{cm}^{-3} \mathrm{~s}^{-1}$.

The analysis of the correlation between the concentrations of nanometer aerosol particles and their charged fraction (positive air ions) showed a good qualitative consistency. Considering different nucleation event days when the concentration of positive intermediate ions (or charged nanometer particles of $2.5-8 \mathrm{~nm}$ ) exceeded $120 \mathrm{~cm}^{-3}$, the linear correlation coefficients varied in the range of $84-98 \%$. The correlation is also good for coarse nanometer particles and their charged fraction $(8-20 \mathrm{~nm})$; the correlation coefficients are in the range of $87-98 \%$. These particles are almost quasisteady state charged. The estimates of the charged fraction of nanometer aerosol particles $(2.5-8 \mathrm{~nm})$ are in the range of $3-6 \%$, which are close to the steady state bipolar charging probability of $2.7 \%$ for the mean size of the fraction of $5.3 \mathrm{~nm}$. Considering the measuring uncertainties, we cannot state that the excess of the charged nanometer particles of positive polarity is an indication of the overcharge of atmospheric aerosols due to an ion-induced nucleation process. Further study is necessary to specify the nucleation mechanism. 
Acknowledgements. This research has in part been supported by the Nessling Foundation, the Nordic Center of Excellence (BACCI), the Estonian Science Foundation through grants 4622 and 6223 and the University of Tartu research project of PP1FY07913.

Edited by: A. Laaksonen

\section{References}

Aalto, P., Hämeri, K., Becker, E., Weber, R., Salm, J., Mäkelä, J. M., Hoell, C., O’Dowd, C. D., Karlsson, H., Hansson, H.-C., Väkevä, M., Koponen, I., Buzorius, G., and Kulmala, M.: Physical characterization of aerosol particles during nucleation events, Tellus, 53B, 344-258, 2001.

Beig, G. and Brasseur, G. P.: Model of tropospheric ion composition: A first attempt, J. Geophys. Res., 105, 22 671-22 684, 2000.

Birmili, W., Berresheim, H., Plass-Dülmer, C., Elste, T., Gilge, S., Wiedensohler, A., and Uhrner, U.: The Hohenpeissenberg aerosol formation experiment (HAFEX): A long-term study including size-resolved aerosol, $\mathrm{H}_{2} \mathrm{SO}_{4}, \mathrm{OH}$, and monoterpenes measurements, Atmos. Chem. Phys., 3, 361-376, 2003, http://www.atmos-chem-phys.net/3/361/2003/.

Birmili, W., Schwirn, K., Nowak, A., Petäjä, T., Rose, D., Hämeri, K., Aalto, P., Wiedensohler, A., Kulmala, M., and Boy, M.: Hygroscopic growth of particle number size distributions at the atmospheric research station Hyytiälä, Finland, Report Series in Aerosol Science (Helsinki), 81A, 62-67, 2006.

Chalmers, J. A.: Atmospheric Electricity, Pergamon Press, Oxford, London, 1967.

Dolezalek, H.: The atmospheric electric fog effect, Rev. Geophys., 1(2), 231-282, 1963.

Eisele, F. L. and Tanner, D. J.: Identification of ions in continental air, J. Geophys. Res., 95, 20 539-20 550, 1990.

Froyd, K. D. and Lovejoy, E. R.: Experimental thermodynamics of cluster ions composed of $\mathrm{H}_{2} \mathrm{SO}_{4}$ and $\mathrm{H}_{2} \mathrm{O}$. 1. Positive ions, J. Phys. Chem. A, 107, 9800-9811, 2003a.

Froyd, K. D. and Lovejoy, E. R.: Experimental thermodynamics of cluster ions composed of $\mathrm{H}_{2} \mathrm{SO}_{4}$ and $\mathrm{H}_{2} \mathrm{O}$. 2. Measurements and ab initio structures of negative ions, J. Phys. Chem. A, 107, 9812-9824, 2003b.

Fuchs, N. A. and Sutugin, A. G.: High-dispersed aerosols, in: Topics in Current Aerosol Research, edited by: Hidy, G. M. and Brock, J. R., vol. 2, pp. 1-60, Pergamon, Oxford, 1971.

Hanson, D. R. and Eisele, F. L.: Measurement of prenucleation molecular clusters in the $\mathrm{NH}_{3}, \mathrm{H}_{2} \mathrm{SO}_{4}, \mathrm{H}_{2} \mathrm{O}$ system, J. Geophys. Res., 107(D12), 4158, doi:10.1029/2001JD001100, 2002.

Hari, P. and Kulmala, M.: Station for Measuring EcosystemAtmosphere Relations (SMEAR II), Boreal Environ. Res., 10, 315-322, 2005.

Hatakka, J., Paatero, J., Viisanen, Y., and Mattsson, R.: Variations of external radiation due to meteorological and hydrological factors in central Finland, Radiochemistry, 40(6), 515-519, MAIK Nauka/ Interperiodica Publishing, 1998.

Hensen, A. and van der Hage, J. C. H.: Parametrization of cosmic radiation at sea level, J. Geophys. Res., 99, 10 693-10 695, 1994.

Hirsikko, A., Laakso, L, Hõrrak, U., Aalto, P. P., Kerminen, V.M., and Kulmala, M.: Annual and size dependent variation of growth rates and ion concentrations in boreal forest, Boreal Env. Res., 10, 357-369, 2005.

Hoppel, W. A.: Ion-aerosol attachment coefficients, ion depletion, and the charge distribution on aerosols, J. Geophys. Res., 90, 5917-5923, 1985.

Hoppel, W. A. and Frick, G. M.: Ion-aerosol attachment coefficients and the steady-state charge distribution on aerosols in a bipolar ion environment, Aerosol Sci. Technol., 5, 1-21, 1986.

Hoppel, W. A. and Frick, G. M.: The nonequilibrium character of the aerosol charge distributions produced by neutralizers, Aerosol Sci. Technol., 12, 471-496, 1990.

Hoppel, W. A., Anderson, R. V., and Willett, J. C.: Atmospheric electricity in the planetary boundary layer, In: The Earth's Electrical Environment, National Academy Press, Washington, D.C., 149-165, 1986.

Hoppel, W. A., Frick, G. M., Fitzgerald, J. W., and Larson, R. E.: Marine boundary layer measurements of new particle formation and the effects nonprecipitating clouds have on aerosol size distribution, J. Geophys. Res., 99, 14 443-14 459, 1994.

Hõrrak, U., Salm, J., and Tammet, H.: Bursts of intermediate ions in atmospheric air, J. Geophys. Res., 103, 13 909-13 915, 1998a.

Hõrrak, U., Mirme, A., Salm, J., Tamm, E., and Tammet, H.: Air ion measurements as a source of information about atmospheric aerosols, Atmos. Res., 46, 233-242, 1998b.

Hõrrak, U., Salm, J., and Tammet, H.: Statistical characterization of air ion mobility spectra at Tahkuse Observatory: Classification of air ions, J. Geophys. Res., 105, 9291-9302, 2000.

Hõrrak, U., Aalto, P., Salm, J., and Kulmala, M.: Characterization of air ions during nucleation events in boreal forest air, Report Series in Aerosol Science (Helsinki), 59, 196-201, 2003a.

Hõrrak, U., Salm, J., and Tammet, H.: Diurnal variation in the concentration of air ions of different mobility classes at a rural area, J. Geophys. Res., 108(D20), 4653, doi:10.1029/2002JD003240, 2003 b.

Hõrrak, U., Tammet, H., Aalto, P. P., and Kulmala, M.: Charge distribution on nanometer aerosol particles in the atmosphere during nucleation burst events, J. Aerosol Sci., 35, S299-S300, 2004a.

Hõrrak, U., Tammet, H., Aalto, P. P., and Kulmala, M.: Study of air ions and nanometer particles in the atmosphere during nucleation burst events, Report Series in Aerosol Science (Helsinki), 71A, 184-189, 2004b.

Hämeri, K., Väkevä, M., Aalto, P. P., Kulmala, M., Swietlicki, E., Zhou, J., Seidl, W., Becker, E., and O’Dowd, C. D.: Hygroscopic and $\mathrm{CCN}$ properties of aerosol particles in boreal forests, Tellus, 53B, 359-379, 2001.

Iida, K., Stolzenburg, M., McMurry, P., Dunn, M. J., Smith, J. N., Eisele, F., and Keady, P.: Contribution of ion-induced nucleation to new particle formation: Methodology and its application to atmospheric observations in Boulder, Colorado, J. Geophys. Res., 111, D23201, doi:10.1029/2006JD007167, 2006.

Israël, H.: Atmospheric Electricity, Vol. I, Israel Program for Scientific Translations, Jerusalem, 1970.

Israël, H.: Atmospheric Electricity, Vol. II, Israel Program for Scientific Translations, Jerusalem, 1973.

Kim, T. O., Adachi, M., Okuyama, K., and Seinfeld, J. H.: Experimental measurement of competitive ion-induced and binary homogeneous nucleation in $\mathrm{SO}_{2} / \mathrm{H}_{2} \mathrm{O} / \mathrm{N}_{2}$ mixtures, Aerosol Sci. Technol., 26, 527-543, 1997.

Kim, T. O., Ishida, T., Adachi, M., Okuyama, K., and Seinfeld, J. 
H.: Nanometer-sized particle formation from $\mathrm{NH}_{3} / \mathrm{SO}_{2} / \mathrm{H}_{2} \mathrm{O} /$ air mixtures by ionizing irradiation, Aerosol Sci. Technol., 29, 111$125,1998$.

Korhonen, P., Kulmala, M., Laaksonen, A., Viisanen, Y., McGraw, R., and Seinfeld, J.: Ternary nucleation of $\mathrm{H}_{2} \mathrm{SO}_{4}, \mathrm{NH}_{3}$ and $\mathrm{H}_{2} \mathrm{O}$ in the atmosphere, J. Geophys. Res., 104, 26 349-26353, 1999.

Kulmala, M., Pirjola, L., and Mäkelä, J. M.: Stable sulphate clusters as a source of new atmospheric particles, Nature, 404, 66-69, 2000.

Kulmala, M., Hämeri, K., Aalto, P. P., Mäkelä, J. M., Pirjola, L., Nilsson, E. D., Buzorius, G., Rannik,Ü., Dal Maso, M., Seidl, W., Hoffman, T., Janson, R., Hansson, H.-C., Viisanen, Y., Laaksonen, A., and O'Dowd, C. D.: Overview of the international project on biogenic aerosol formation in the boreal forest (BIOFOR), Tellus, 53B, 324-343, 2001a.

Kulmala, M., Dal Maso, M., Mäkelä, J. M., Pirjola, L., Väkevä, M., Aalto, P. P., Miikkulainen, P., Hämeri, K., and O’Dowd, C. D.: On the formation, growth and composition of nucleation mode particles, Tellus, 53B, 479-490, 2001b.

Kulmala, M., Vehkamäki, H., Petäjä, T., Dal Maso M., Lauri, A., Kerminen, V.-M., Birmili, W., and McMurry, P. H.: Formation and growth rates of ultrafine atmospheric particles: a review of observations, J. Aerosol Sci., 35, 143-176, 2004a.

Kulmala, M., Laakso, L., Lehtinen, K. E. J., Riipinen, I., Dal Maso, M., Anttila, T., Kerminen, V.-M., Hõrrak, U., Vana, M., and Tammet, H.: Initial steps of aerosol growth, Atmos. Chem. Phys., 4, 2553-2560, 2004b.

Laakso L., Mäkelä, J. M., Pirjola, L., and Kulmala, M.: Model studies on ion-induced nucleation in the atmosphere, J. Geophys. Res., 107(D20), 4427, doi:10.1029/2002JD002140, 2002.

Laakso, L., Petäjä, T., Lehtinen, K. E. J., Kulmala, M., Paatero, J., Hõrrak, U., Tammet, H., and Joutsensaari, J.: Ion production rate in a boreal forest based on ion, particle and radiation measurements, Atmos. Chem. Phys., 4, 1933-1943, 2004a.

Laakso, L., Anttila, T., Lehtinen, K. E. J., Aalto, P. P., Kulmala, M., Hõrrak, U., Paatero, J., Hanke, M., and Arnold, F.: Kinetic nucleation and ions in boreal forest particle formation events, Atmos. Chem. Phys., 4, 2353-2366, 2004b.

Lovejoy, E., Curtius, J., and Froyd, K.: Atmospheric ion-induced nucleation of sulfuric acid and water, J. Geophys. Res., 109, doi:10.1029/2003JD004460, 2004.

Luts, A. and Parts, T.-E.: Evolution of negative small air ions at two different temperatures, J. Atmos. Solar-Terr. Phys., 64, 763-774, 2002.

Mäkelä, J. M., Dal Maso, M., Pirjola, L., Keronen, P., Laakso, L., Kulmala, M., and Laaksonen, A.: Characteristics of the aerosol particle formation events observed at a boreal forest site in southern Finland, Boreal Environ. Res., 4, 299-313, 2000.

Mäkelä, J. M., Salm, J., Smirnov, V. V., Koponen, I., Paatero, J., and Pronin, A. A.: Electrical charging state of fine and ultrafine particles in boreal forest air, J. Aerosol Sci., 32, S149-S150, 2001 a.

Mäkelä, J. M., Yli-Koivisto, S., Hiltunen, V., Seidl, W., Swietlicki, E., Teinilä , K., Sillanpää, M., Koponen, I. K., Paatero, J., Rosman, K., and Hämeri, K.: Chemical composition of aerosol during particle formation events in Boreal forest, Tellus, 53B, 380393, $2001 b$.

Mäkelä, J. M., Salm, J., Smirnov, V. V., Koponen, I., Paatero, J., and Pronin, A. A.: Measurements of the mobility distribution of air ions as a source of information for the study of aerosol generation, In: Proceedings of 12th International Conference on Atmospheric Electricity, 2003, Versailles, 793-796, 2003.

Nadykto, A. and Yu, F.: Uptake of neutral polar vapour molecules by charged particles: Enhancement due to dipole-charge interaction, J. Geophy. Res., 108(D23), 4717, doi:10.1029/2003JD003664, 2003.

Nagato, K. and Ogawa, T.: Evolution of tropospheric ions observed by an ion mobility spectrometer with a drift tube, J. Geophys. Res. 103, 13 917-13 925, 1998.

Napari, I., Kulmala, M., and Vehkamäki, H.: Ternary nucleation of inorganic acids, ammonia, and water, J. Chem. Phys., 117, 8418-8425, 2002.

Nilsson, E. D., Paatero, J., and Boy, M.: Effects of air masses and synoptic weather on aerosol formation in the continental boundary layer, Tellus, 53B, 462-478, 2001a.

Nilsson, E. D., Rannik, Ü., Buzorius, G., O’Dowd, C., Boy, M., Paatero J., and Laakso, L.: Effects of the continental boundary layer evolution, convection, turbulence and entrainment on aerosol formation, Tellus, 53B, 441-461, $2001 \mathrm{~b}$.

Parts, T.-E. and Luts, A.: Observed and simulated effects of certain pollutants on small air ion spectra: I. Positive ions, Atmos. Environ., 38, 1283-1289, 2004.

Penttinen, L., Paatero, J., Viisanen, Y., and Kulmala, M.: Seasonal and diurnal variation of airbone radon-222 at Hyytiälä, Finland, Report Series in Aerosol Science (Helsinki), 59, 79-82, 2003.

Porstendörfer, J.: Properties and behaviour of radon and thoron and their decay products in the air, J. Aerosol Sci., 25, 219-263, 1994.

Raes, F. and Janssens, A.: Ion-induced aerosol formation in a $\mathrm{H}_{2} \mathrm{O}$ $\mathrm{H}_{2} \mathrm{SO}_{4}$ system. I. Extension of the classical theory and search for experimental evidence, J. Aerosol Sci., 16, 217-227, 1985.

Raes, F. and Van Dingenen, R.: Simulation of condensation and cloud condensation nuclei from biogenic $\mathrm{SO}_{2}$ in the remote marine boundary layer, J. Geophys. Res., 97, 12 901-12 912, 1992.

Ramamurthi, M., Strydom, R., Hopke, P. K., and Holub, R. F.: Nanometer and ultrafine aerosols from radon radiolysis, J. Aerosol Sci., 24, 393-407, 1993.

Reischl, G. P., Mäkelä, J. M., Karch, R., and Necid, J.: Bipolar charging of ultrafine particles in the size range below $10 \mathrm{~nm}, \mathrm{~J}$. Aerosol Sci., 27, 931-949, 1996.

Svenningsson, B., Rissler, J., Swietlicki, E., Mircea, M., Bilde, M., Facchini, M. C., Decesari, S., Fuzzi, S., Zhou, J., Mønster, J., and Rosenørn, T.: Hygroscopic growth and critical supersaturations for mixed aerosol particles of inorganic and organic compounds of atmospheric relevance, Atmos. Chem. Phys., 6, 1937-1952, 2006, http://www.atmos-chem-phys.net/6/1937/2006/.

Tamm, E., Hõrrak, U., Mirme, A., and Vana, M.: On the charge distribution on atmospheric nanoparticles, J. Aerosol Sci., 32, S347-S348, 2001.

Tammet, H.: The aspiration method for the determination of atmospheric ion-spectra, Israel Program for Scientific Translations, Jerusalem, 1970.

Tammet, H.: Aerosol electrical density: Interpretation and principles of measurement, Report Series in Aerosol Science (Helsinki), 19, 128-133, 1991.

Tammet, H. and Kimmel, V.: Electrostatic deposition of radon daughter clusters on the trees, J. Aerosol Sci., 29, S473-S474, 1998. 
Tammet, H., Kimmel, V., and Israelsson, S.: Effect of atmospheric electricity on dry deposition of airborne particles from atmosphere, Atmos. Environ., 35, 3413-3419, 2001.

Tammet, H., Hõrrak, U., Laakso, L., and Kulmala, M.: Factors of air ion balance in a coniferous forest according to measurements in Hyytiälä, Finland, Atmos. Chem. Phys., 6, 3377-3390, 2006, http://www.atmos-chem-phys.net/6/3377/2006/.

Tunved, P., Hansson, H.-C., Kulmala, M., Aalto, P., Viisanen, Y., Karlsson, H., Kristensson, A., Swietlicki, E., Dal Maso, M., Strom, J., and Komppula, M.: One year boundary layer aerosol size distribution data from five nordic background stations, Atmos. Chem. Phys., 3, 2183-2205, 2003, http://www.atmos-chem-phys.net/3/2183/2003/.

Vesala, T., Haataja, J., Aalto, P., Altimir, N., Buzorius, G., Garam, E., Hämeri, K., Ilvesniemi, H., Jokinen, V., Keronen, P., Lahti, T., Markkanen, T., Mäkelä, J.M., Nikinmaa, E., Palmroth, S., Palva, L., Pohja, T., Pumpanen, J., Rannik, Ü., Siivola, E., Ylitalo, H., Hari, P., and Kulmala, M.: Long-term field measurements of atmosphere-surface interactions in boreal forest combining forest ecology, micrometeorology, aerosol physics and atmospheric chemistry, Trends in Heat, Mass and Momentum Transfer, 4, 1735, 1998 .
Wex, H., Kiselev, A., Stratmann, F., Zoboki, J., and Brechtel, F.: Measured and modeled equilibrium sizes of $\mathrm{NaCl}$ and $\left(\mathrm{NH}_{4}\right)_{2} \mathrm{SO}_{4}$ particles at relative humidities up to $99.1 \%$, J. Geophys. Res., 110, D21212, doi:10.1029/2004JD005507, 2005.

Wilhelm, S., Eichkorn, S., Wiedner, D., Pirjola, L., and Arnold, F.: Ion-induced aerosol formation: new insights from laboratory measurements of mixed cluster ions $\mathrm{HSO}_{4}^{-}\left(\mathrm{H}_{2} \mathrm{SO}_{4}\right)_{a}\left(\mathrm{H}_{2} \mathrm{O}\right)_{w}$ and $\mathrm{H}^{+}\left(\mathrm{H}_{2} \mathrm{SO}_{4}\right)_{a}\left(\mathrm{H}_{2} \mathrm{O}\right)_{w}$, Atmos. Environ., 38, 1735-1744, 2004.

Yu, F. and Turco, R. P.: Ultrafine aerosol formation via ionmediated nucleation, Geophys. Res. Lett., 27, 883-886, 2000.

Yu, F. and Turco, R. P.: From molecular clusters to nanoparticles: Role of ambient ionization in tropospheric aerosol formation, J. Geophys. Res., 106, 4797-4814, 2001.

Zhou, J., Swietlicki, E., Berg, O. H., Aalto, P. P., Hämeri, K., Nilsson, E. D., and Leck, C.: Hygroscopic properties of aerosol particles over the central Arctic Ocean during summer, J. Geophys. Res., 106, 32 111-32 123, 2001. 